\title{
Transferable Gaussian attractive potentials for organic/oxide interfaces.
}

\author{
Jérôme Rey, ${ }^{\prime+}$, Sarah Blanck ${ }^{12+}$, Paul Clabaut', Sophie Loehléz, Stephan N. Steinmann ${ }^{\prime *}$, \\ Carine Michel ${ }^{\prime *}$
}

Université de Lyon, École Normale Supérieure de Lyon, CNRS UMR 5182, Laboratoire de Chimie, 46 allée d'Italie, F69364 Lyon, France

2 Total Marketing \& Services, Chemin du Canal - BP 22, 69360, Solaize, France

\section{AUTHOR INFORMATION \\ Corresponding Authors \\ *stephan.steinmann@ens-lyon.fr \\ *carine.michel@ens-lyon.fr}

\section{First Authors:}

$\$$ J.R. and S.B. equally contributed to this work.

KEYWORDS. Force Fields; Alumina; Hematite; Adsorption; Organic Surface Films

\begin{abstract}
.
Organic/oxide interfaces play an important role in many areas of chemistry, and in particular for lubrication and corrosion. Molecular dynamics simulations are the method of choice for providing complementary insight to experiments. However, the force fields used to simulate the interaction between molecules and oxide surfaces tend to capture only weak physisorption interactions, discarding the stabilizing Lewis acid/base interactions. We here propose an improvement of the usual molecular mechanics description (based on Lennard-Jones and electrostatic interactions) by addition of an attractive Gaussian potential between reactive sites of the surface and heteroatoms of adsorbed organic molecules, leading to the GLJ potential.
\end{abstract}


The interactions of four oxygenated and four amine molecules with the typical and widespread hematite and $\gamma$-alumina surfaces are investigated. The total RMSD for all probed molecules decreases from 29.2 to $5.7 \mathrm{kcal} / \mathrm{mol}$, and the corresponding percentage from 107.4 to $22.6 \%$ over hematite, while on $\gamma$-alumina the RMSD decreases from 21.5 to $7.6 \mathrm{kcal} / \mathrm{mol}$, despite using a single parameter for all five chemically inequivalent surface aluminum atoms. Applying GLJ to the simulation of n-octadecanamine and N-tetradecyldiethanolamine adsorbed films on hematite and alumina respectively demonstrates that mobility of the surfactants is overestimated by the common LJ potential, while GLJ shows a strong structuration and slow dynamics of the surface films, as could be expected from the firstprinciples adsorption energies for model head-groups.

\section{INTRODUCTION}

Oxide/organic interfaces play a critical role in a wide range of fields, such as heterogeneous catalysis, ${ }^{1,2}$ (photo)electrochemistry, ${ }^{3}$ biological ${ }^{1-10}$ and geological ${ }^{1,1,2}$ interfaces (with the specific case of nanoconfined liquids ${ }^{13}$ ), corrosion ${ }^{14}$ and lubrication..$^{15,16}$ In this paper, we will focus on modeling the interaction of organic molecules with typical oxide surfaces of utmost importance: the hematite (0001) surface ${ }^{17}$ as well as the $\gamma$-alumina (100) and (110) surfaces. ${ }^{18}$ Hematite $\left(\alpha-\mathrm{Fe}_{2} \mathrm{O}_{3}\right)$ is a common material, observed in minerals ${ }^{17.19}$ or formed on iron-containing alloys.$^{20}$ Surface properties of hematite are crucial for flotation (useful for resource recovery), wettability, control of water and impurities on steel surfaces, ${ }^{21-23}$ or photocatalysis e.g. photoelectrochemical solar water splitting. ${ }^{24}$ On the one hand, $\gamma$-alumina is a widespread support in heterogeneous catalysis for many processes ranging from petroleum industries to biomass conversion. ${ }^{25}$ The understanding of its interface with liquid water and organic molecules is a key point to improve its stability in presence of liquid water. ${ }^{26-28}$ On the other hand, $\gamma$-alumina is a model for surface oxidized aluminum. Thus, the interaction of $\gamma$-alumina with organic molecules is important for metal working, where the understanding of the interactions between the lubricant and the surface is essential to predict the performances of the lubricant. ${ }^{x}$

$A b$ initio methods are the most versatile and accurate tools when bond breaking and bond formation are involved. This is a typical phenomenon at oxide/organic interfaces when Lewis acid/base chemisorption is involved. Oxide/organic interfaces have been previously investigated using an ab initio molecular dynamics description at the DFT level. ${ }^{2830-32}$ However, the computational cost of DFT is extremely high which implies typical trajectories of a few 
tens of picoseconds and thus a limited sampling. This contrasts with the requirements for modeling of interfacial structuration, which typically requires trajectories of about a nanosecond. These time-scales can only be reasonably reached with cheaper simulations methods, i.e., relying on force fields. The latter are usually developed for solids or liquids but are rarely specifically addressing the interactions at the interface between the surface and the molecules or ions which constitute the liquid. Most physics-based force fields consider that the interactions at the interface are driven by physisorption and can thus be described by nonbonding terms (i.e. Lennard-Jones (LJ) and electrostatic potentials). Following this philosophy, Lennard-Jones potentials have been fitted to describe the interactions between metals and organic molecules ${ }^{33}$ and the Interface Force Field (IFF) has been developed. ${ }^{34}$ The CLAY force field, ${ }^{35}$ designed for clay minerals and other metallic oxides such as hematite and alumina, has also been used to study interfaces. In particular the alumina interface with liquid water ${ }^{36}$ or ethanol, ${ }^{37}$ the nucleation of water ${ }^{38}$ or the detachment of oil molecules, ${ }^{39}$ but also the interface of hematite with water ${ }^{40,41}$ or with glycol ${ }^{42}$ have been investigated. However, DFT computations on these oxide surfaces show that Lewis bases (typically $\mathrm{O}$ or $\mathrm{N}$ functionalized organic molecules) interact strongly (tens of $\mathrm{kcal} / \mathrm{mol}$ and interatomic distances below $2 \AA$ ) with the exposed $\mathrm{Al}$ or Fe atoms of alumina and hematite respectively (Lewis acid sites). ${ }^{29,43-}$ 46 Given these strong and anisotropic interactions it is questionable whether LJ-based force fields are suitable for their description, motivating the development of additional non-bonding force field terms that are able to describe stronger interactions. Compared to the pair-wise additive LJ potentials, more elaborated many body interfacial potentials are well documented in the literature for metal-water interaction. ${ }^{47-49}$ More generally, ReaxFF ${ }^{50}$ can describe reactive events at the interface, although at the expense of a challenging, system dependent, parametrization. ${ }^{51-53}$ Moving away from the physics-based force field paradigm, machine learning force fields in the form of artificial neural networks or kernel-ridge regression are in rapid expansion, promising high accuracy due to their highly flexible mathematical form. ${ }^{54-58}$ For instance, this type of force fields have been recently used to investigate the solid/liquid copper/water ${ }^{59}$ and zinc oxide/water ${ }^{60}$ interfaces, or to identify the active sites on dealloyed gold surfaces. ${ }^{61}$ While these methods appear very promising, the training of such a potential and more importantly its transferability is still challenging and requires a tremendous amount of training data. ${ }^{62}$

The strategy developed here is a simple and transferable improvement of usual LJ-based force fields, aiming at significantly better results with a low computational and parametrization cost. It is inspired by our previous work on metal/water interface where we proposed the efficient 
GAL force fields that improve both the strength of adsorption and the angular orientation. ${ }^{4963}$ To minimize the computational burden and its implementation, we herein focus on the improvement of the adsorption strength and its corrugation over the surface. This is achieved by supplementing the existing CLAYFF Lennard-Jones force field (LJ) with an anisotropic attractive Gaussian potential, resulting in a Gaussian-Lennard-Jones force field (GLJ). The anisotropic attractive Gaussian potential, at heart of the GAL force fields, is here centered on Lewis-acid sites ( $\mathrm{Fe}$ or $\mathrm{Al}$ for alumina and hematite respectively) of the surface and acts on $\mathrm{O}$ and $\mathrm{N}$ atoms of adsorbates. The fitting set and procedure can be found in Section 2, while the GLJ performance and transferability is assessed in section 3. In the last section, the impact of this force field improvement on the structuration of two organic film structuration is discussed: aliphatic primary amines on hematite and $\mathrm{N}$-tetradecyldiethanolamines on (100) $\gamma$-alumina.

\section{METHODOLOGY}

\section{DFT calculations}

DFT calculations were performed within the CP2K 5.1 framework, ${ }^{64}$ using the PBE generalized gradient approximation functional ${ }^{65}$ and the Grimme D3 dispersion correction including C9 terms. ${ }^{66,67}$ GTH pseudo potentials ${ }^{68-71}$ describe the core electrons. A mixed Gaussian and plane waves $(\mathrm{GPW})^{72,73}$ method was adopted. The valence electron density was developed on a double-zeta DZVP-MOLOPT basis set, while the auxiliary plane wave basis set had a cutoff energy of 400 Ry. During the self-consistent field process (SCF), the energies were converged to $10^{-6} \mathrm{Ha}$. As hematite is an antiferromagnetic oxide, ${ }^{43,74}$ the DFT $+\mathrm{U}$ method was applied for this case, with (U-J) set to $5 \mathrm{eV}$ to take into account the strong electronic correlation of the iron $3 \mathrm{~d}$ electrons. ${ }^{43}$

The bulk structures of hematite and $\gamma$-alumina were optimized to forces below $4.5 \times 10^{-4}$ $\mathrm{Ha} /$ bohr. The hematite bulk was described by a $\mathrm{p}(3 \times 3 \times 1)$ unit cell and the Brillouin zone sampling was restricted to the $\Gamma$-point. The $\gamma-\mathrm{Al}_{2} \mathrm{O}_{3}$ bulk structure is taken from Digne's bulk model. ${ }^{18,75}$ Its geometry was optimized using a $\mathrm{p}(1 \times 1 \times 1)$ unit cell also together with a $(3 \times 2 \times 2)$ Monkhorst-Pack ${ }^{76}$ k-point grid.

\section{Surface slab models and molecule adsorption at the DFT level}

The surfaces were cleaved from the optimized bulk using a slab of at least $10 \AA$ thickness and a vacuum of at least $30 \AA$, the coordinates and setup are available in the SI. The central symmetry is preserved, ensuring that the total dipole moment is zero. The slabs were frozen in their bulk geometry during all computations. Geometry optimization of molecules on the frozen 
surfaces were conducted in order to determine the optimal adsorption coordinates for the anchoring atom of each system. These calculations were converged to forces below $4.5 \times 10^{-4}$ $\mathrm{Ha} /$ bohr. Due to the large size of the slabs, Brillouin zone sampling was restricted to the $\Gamma$ point.

The (0001) surface of $\alpha-\mathrm{Fe}_{2} \mathrm{O}_{3}$ is widely used both as a catalyst ${ }^{17,7}$ and as a model for steel surfaces ${ }^{78,79}$ It is described here using a $\mathrm{p}(3 \times 3)$ cell. The primitive cell is represented in Figure 1.a showing that only one type of iron atom is exposed at the surface.

$\gamma-\mathrm{Al}_{2} \mathrm{O}_{3}$ is known to expose not only its most stable surface, namely the (100), but also the (110), thus exposing a variety of Al sites..$^{18,7}$ The corresponding slabs were prepared by cleavage of the bulk, yielding a $\mathrm{p}(4 \times 3)$ unit cell for the $(100)$ surface and a $\mathrm{p}(2 \times 2)$ unit cell for the (110) surface. On the (100) surface (Figure 1.b), all three non-equivalent aluminum atoms are truncated octahedral aluminums coordinated to five oxygen atoms. They are labelled $\mathrm{Al}_{\mathrm{va}}, \mathrm{Al}_{\mathrm{vb}}$ and $A_{v c}$. The fourth exposed $A l$ is equivalent to $A l_{v b}$ and is labelled $A l_{v b}$. The (110) surface (Figure 1.c), features one truncated tetrahedral aluminum atom coordinated to three oxygen atoms, labelled $\mathrm{Al}_{\Perp}$, which is the most reactive one and two non-equivalent truncated octahedral aluminum atoms, $\mathrm{Al}_{\mathrm{Na}}$ and $\mathrm{Al}_{\mathrm{Nv}}$, coordinated to four oxygen atoms.

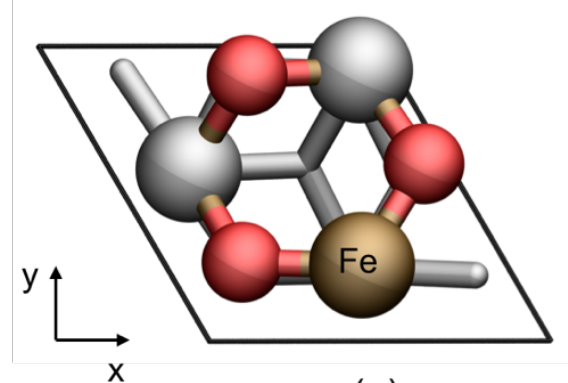

(a)

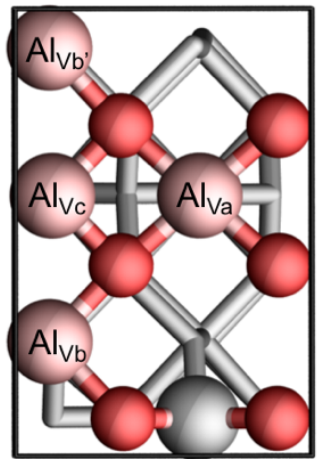

(b)

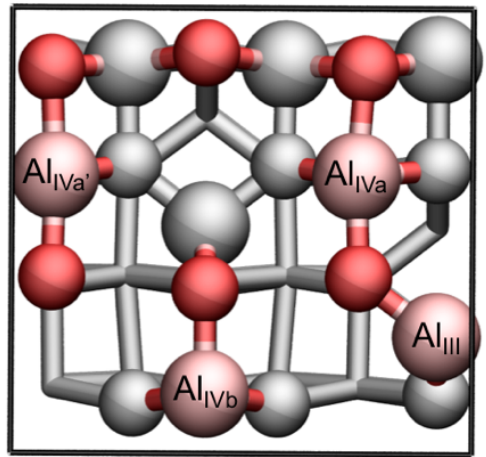

(c)

Figure 1. Top view of the $\mathrm{p}(1 \times 1)$ unit cell of (a) the (0001) $\mathrm{Fe}_{2} \mathrm{O}_{3}$ surface, (b) the (100) $\gamma-\mathrm{Al}_{2} \mathrm{O}_{3}$ surface and (c) the (110) $\gamma-\mathrm{Al}_{2} \mathrm{O}_{3}$ surface. Only exposed atoms are colored (Fe in brown, $\mathrm{Al}$ in pink and $\mathrm{O}$ in red). Only the first two atomic layers are shown with balls. Equivalent sites are distinguished by a prime.

\section{Molecular Mechanics}

Molecular mechanics calculations were also performed with a modified version of CP2K 5.1. ${ }^{64}$ The smooth particle-mesh Ewald summation ${ }^{80}$ was applied to evaluate the long-range Coulombic interactions. The width parameter was set to $0.36 \AA^{-1}$ and a grid with about 1 point per $\AA$ of the corresponding unit-cell length was used. 
The Lennard-Jones parameters and the charges of hematite and alumina surfaces were taken from the CLAYFF force field ${ }^{35}$ (see Table S1). The GAFF force field ${ }^{81}$ was adopted for organic molecules with Gasteiger charges ${ }^{82}$ assigned by Open Babel (Table S2) ${ }^{83}$ whereas water molecules were described with the flexible TIP3P model. ${ }^{84,85}$ As implemented in Ambertools, ${ }^{86}$ the Lorentz/Berthelot combining rules were used for interactions involving different atom types. This level of theory is referred to as LJ later on, since the interfacial interactions are only treated through Lennard-Jones potentials and point charges.

In order to improve the description of the interaction of organic molecules with the Lewis acid sites of the surfaces, anisotropic attractive Gaussian potentials between surface metal atoms $\operatorname{Met}(\mathrm{Al}$ or $\mathrm{Fe}$ ) and heteroatoms Het ( $\mathrm{N}$ or $\mathrm{O})$ of the organic molecules were added. The general expression of this potential for a given Met-Het interaction is as follows:

$$
V_{\text {Met-Het }}\left(r_{x y}, r_{z}\right)=A e^{-b_{x y} r_{x y}^{2}} e^{-b_{z} r_{z}^{2}},
$$

where $A$ is the magnitude of the Gaussian attraction, $r_{x y}$ and $r_{z}$ are the Met-Het distances in the $(x, y)$ plane and the out of plane $(z)$ direction respectively, $b_{x y}$ and $b_{z}$ are the corresponding width parameters of the Gaussian. The three parameters $A, b_{x y}$ and $b_{z}$ are defined independently for each Met-Het pair.

When the LJ level of theory is supplemented by this extra attractive potential, it will be referred to as GLJ and the corresponding total energy writes:

$$
E_{G L J}=E_{L J}+E_{\text {Gaussian }}
$$

where $E_{L J}=E_{C L A Y F F / G A F / T I P 3 P}$ is the molecular mechanics energy computed with the relevant force fields and $E_{\text {Gaussian }}$ is the sum of the $V_{\text {Met-Het }}$ potentials.

\section{Fitting set and procedure}

We parametrized the attractive Gaussian for four Met-Het interactions: Fe-O, Fe-N, Al-O, Al$\mathrm{N}$, which correspond to 12 parameters. To do so, we chose a specific organic molecule (dimethylether for $\mathrm{O}$ and dimethylamine for $\mathrm{N}$ ) and a specific site for $\mathrm{Al}$ (the $\mathrm{Al}_{\mathrm{va}}$ site, which is the most reactive one of the (100) surface ${ }^{29,75}$ ), while hematite (0001) exposes only one type of iron atoms.

The positions of adsorption sites $\left(x_{o p,}, y_{o p}, z_{o p r}\right)$ were defined as the position of the $\mathrm{O}$ or $\mathrm{N}$ atom of the adsorbed molecule (dimethylether or dimethylamine) determined at the DFT level. The structures of the fitting set were defined as translation of the molecule with respect to this site using a grid detailed in SI (section S.1.2), corresponding to 159 data points for the alumina 
surface and 126 for hematite. Internal coordinates of the molecule were replaced by the one of the gas phase geometry at the corresponding level of theory, i.e. DFT or GAFF/TIP3P.

The interaction energy is defined in Eq. 3:

$$
\Delta E_{\text {int }}=E_{\text {mol@slab }}-E_{\text {mol }}-E_{\text {slab }}
$$

where $E_{\text {mol@slab }}, E_{\text {mol }}$ and $E_{\text {slab }}$ are the electronic energies of the molecule on the slab, the molecule in vacuum and the slab, respectively.

The parameters $A, b_{x y}$ and $b_{z}$ were adjusted in such a way that the computed GLJ interaction energy $\Delta E_{\text {int }}$ closely reproduces the DFT one (see Figure S1 in supporting information). The values of these parameters are given in Table 1.

\begin{tabular}{|c|c|c|c|}
\hline Met-Het & $A(\mathrm{kcal} / \mathrm{mol})$ & $\begin{array}{c}b_{x y} \\
\left(\AA^{-2}\right)\end{array}$ & $\begin{array}{c}b_{z} \\
\left(\AA^{-2}\right)\end{array}$ \\
\hline Fe-O & -120 & 0.3 & 0.4 \\
\hline Fe-N & -231 & 0.3 & 0.4 \\
\hline Al-O & -51 & 0.5 & 0.2 \\
\hline Al-N & -90 & 0.6 & 0.2 \\
\hline
\end{tabular}

Table 1. Fitted parameters for the attractive Gaussian potential for four metal-heteroatoms (Met-Het) interactions

\section{Validation set}

We assessed the transferability of the Gaussian parameters obtained from dimethylether and dimethylamine to other molecules (methanol, acetone and water for Met-O interaction and ammonia, methylamine and trimethylamine for Met-N interaction). Similarly, the transferability of the Al-Het parameters fitted on the $\mathrm{Al}_{\mathrm{va}}$ site was tested on the other sites of the $\gamma$-alumina (100) and (110) surfaces.

Interaction energies were defined and computed consistently with the fitting set on an extensive grid designed to include the attractive potential wells found on each surface but also some more repulsive regions of the potential energy surface. More details about the grid we used are provided in the SI (Section S.1.3).

The performance of the LJ and GLJ were assessed against the DFT interaction energies, but discarding the structures corresponding to an endothermic interaction at the DFT level $\left(\Delta \mathrm{E}_{\text {in }}(\mathrm{DFT})>0\right)$ and the data where the repulsive part of potential energy in LJ was too repulsive $\left(\Delta \mathrm{E}_{\mathrm{int}}(\mathrm{LJ})>40 \mathrm{kcal} / \mathrm{mol}\right)$ since they typically correspond to structures generated along $\mathrm{z}$ axis at $z_{\text {opt }}-0.25 \AA$ and only show that the Lennard-Jones potential is too repulsive at short distance, a well-known failure.$^{87-0}$ 


\section{Applications}

Applications showing the influence of the presence of the Gaussian potentials on the formation of organic films are presented in Section 4 on two different systems. For both cases, we ran a 1 ns molecular dynamic simulations at the LG and GLJ level of theory of long chain organic molecules over a completely frozen alumina or hematite slab using a 0.5 fs timestep. The temperature was set to $300 \mathrm{~K}$ using the Nose-Hoover thermostat. The trajectory was then analyzed removing the first 300 ps corresponding to the equilibration of the system.

The systems were built in the following way: the organic molecules were placed in a $30 \AA$ high box using PACKMOL" ${ }^{n}$, at a $2 \AA$ distance perpendicularly to the considered surface. A $30 \AA$ vacuum layer was then added on top of the molecules to avoid interactions between two periodically repeated systems.

We first studied n-octadecanamine on hematite. 36 molecules were randomly placed in the 30 $\AA$ high box over a p (6x6) hematite slab. The number of molecules corresponds to the 36 iron atoms exposed on the $\mathrm{p}(6 \times 6)$ hematite slab.

The second application presented in this paper is the film formation of $\mathrm{N}$ tetradecyldiethanolamine molecules on a p(4x3) (100) $\gamma$-alumina surface. For this study, 12 molecules were put in the packmol box on the top of the alumina slab. In this case the polar head group was forced to be oriented towards the surface by construction.

\section{Force Field performance}

\subsection{Transferability among molecules on hematite surface}

In this section, we assess the transferability of the Gaussian parameters obtained for the $\mathrm{Fe}-\mathrm{O}$ and Fe-N interactions using dimethylether and dimethylamine respectively to other molecules: methanol, water and acetone for oxygenated molecules; methylamine, ammonia and trimethylamine for nitrogenated molecules. Interaction energies for these two sets of four molecules were computed at different heights over the adsorption site, as explained in Section 2 and the results are shown in Figure 2, where the root mean square percentage deviation (RMPD) is given for the entire set, but also individually for each molecule. 
a)

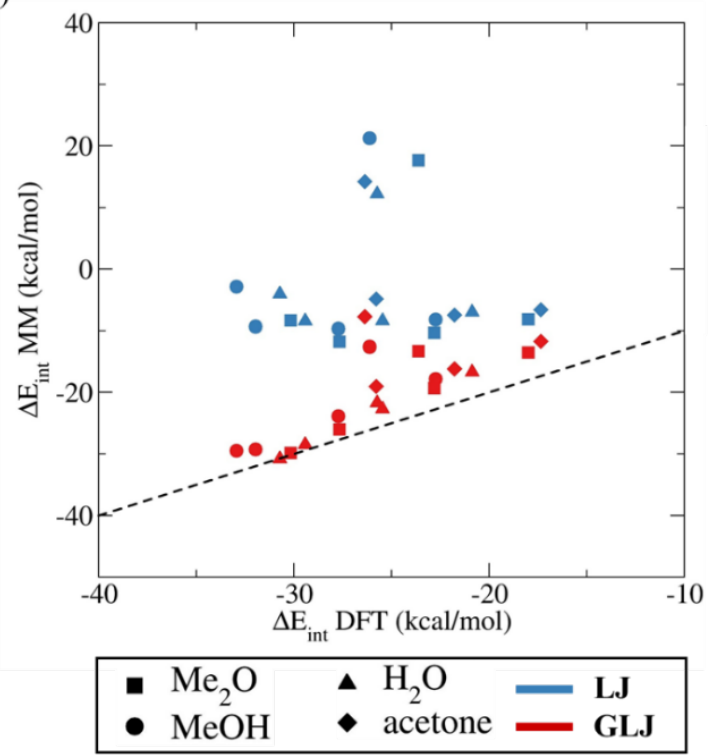

b)

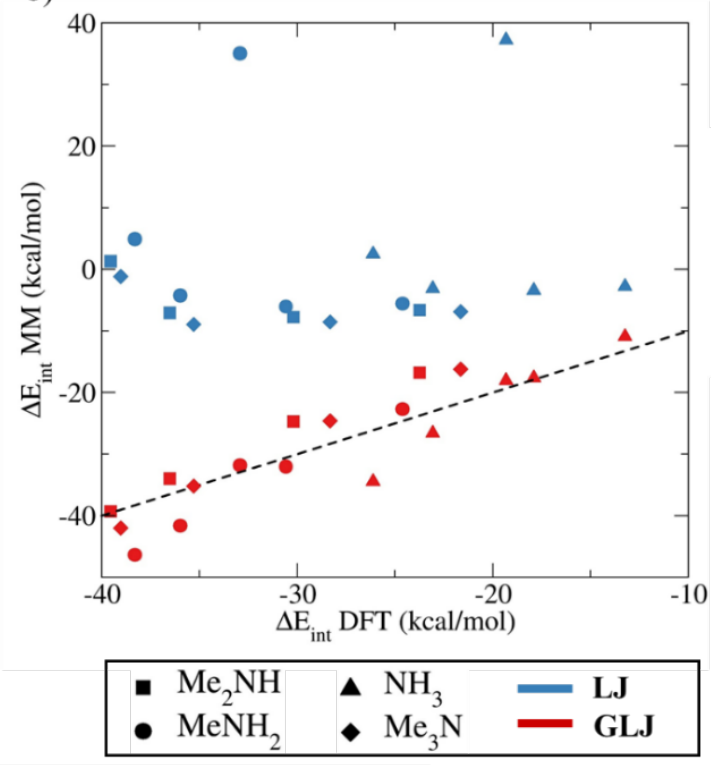

c)

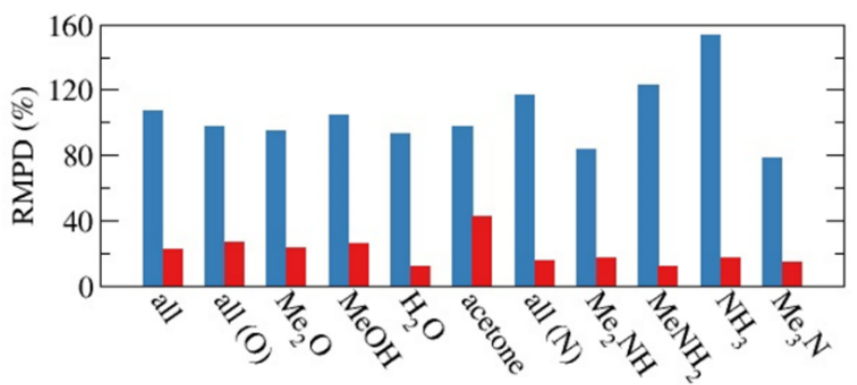

Figure 2. Comparison of the interaction energies of a) oxygenated molecules and b) amines on the hematite (0001) surface computed at the MM level (LJ in blue, GLJ in red) and DFT. c) Corresponding RMPD bar plot.

The interaction energy is systematically too weak for $\mathrm{LJ}$, and some structures give unrealistic endothermic interaction above $10 \mathrm{kcal} / \mathrm{mol}$. Hence, the performance of $\mathrm{LJ}$ with respect to DFT is poor. GLJ results are much closer to DFT and yield to much stronger, always exothermic, interactions. The root mean square deviation (RMSD) for each molecule is between 2.9 and $6.9 \mathrm{kcal} / \mathrm{mol}$ for GLJ (between $12.6 \%$ to $27.5 \%$ ), to be compared with 23.2 to $41.1 \mathrm{kcal} / \mathrm{mol}$ (78.3 to $153.5 \%)$ for $\mathrm{LJ}$.

Acetone is the worst case for GLJ (RMSD of $10.7 \mathrm{kcal} / \mathrm{mol}$ and RMPD of $43 \%$ for GLJ, versus $24.5 \mathrm{kcal} / \mathrm{mol}$ and $98 \%$ for $\mathrm{LJ})$. This does not completely come as a surprise, given that it is the only molecule with a sp2, rather than a sp3 oxygen atom. Moreover, as can be seen in Figure 3, the LJ repulsive part of the potential is too strong. Since the Gaussian attraction cannot compete with the $\mathrm{r}^{12}$ repulsive wall, this misrepresentation cannot be corrected with the GLJ potential. 
In summary, the transferability of the GLJ parameters, fitted on the dimethylether $\mathrm{Me}_{2} \mathrm{O}$ or dimethylamine $\mathrm{Me}_{2} \mathrm{~N}$, to other molecules leads to a very significant improvement (the global RMPD, for all molecules, decreases from 107 to 23\% - see Table S3). This first success of our approach is encouraging, so that we move on to the question of transferability between sites.

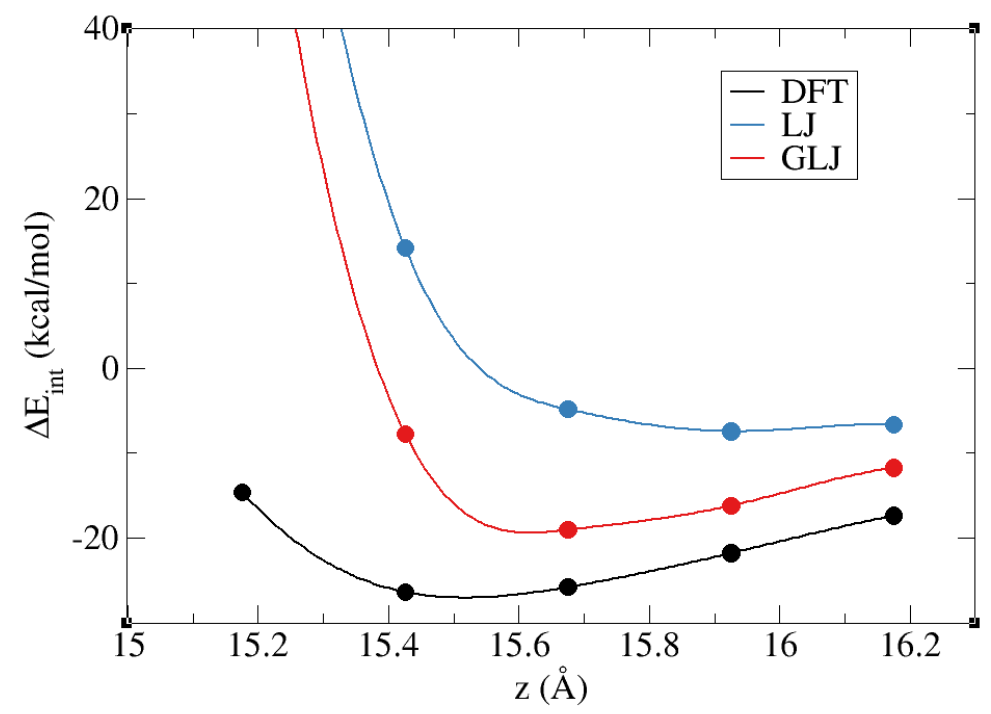

Figure 3. Interaction energies of acetone with the reactive site of hematite as a function of $\mathrm{z}$.

\subsection{Transferability among sites on alumina surface}

The transferability of the Gaussian parameters determined for the Alva to the other five aluminum atoms exposed on $\gamma$-alumina (100) and (110) surfaces (see Figure 1) was tested with one probe molecule per Al-Het interaction (dimethylether and dimethylamine). The intrinsic acidity ranking of the surface Lewis acid sites is known to be the following: $\mathrm{Al}_{\mathrm{III}}>\mathrm{Al} \mathrm{l}_{\mathrm{Va}} \sim$ $\mathrm{Al}_{\text {IVb }}>\mathrm{Al}_{\text {Iva }}>\mathrm{Al}_{\mathrm{Vb}}>\mathrm{Al}_{\mathrm{Vc}}{ }^{75}$ The GLJ parameters was adjusted on the $\mathrm{Al}_{\mathrm{Va}}$ site which is of an intermediate acidity and therefore significantly less reactive than $\mathrm{Al}_{\text {III }}$ and close to $\mathrm{Al}_{\mathrm{IVb}}$. The values of interaction energies computed at molecular mechanics levels (LJ and GLJ) are plotted against the DFT interaction energies in Figure 4. 

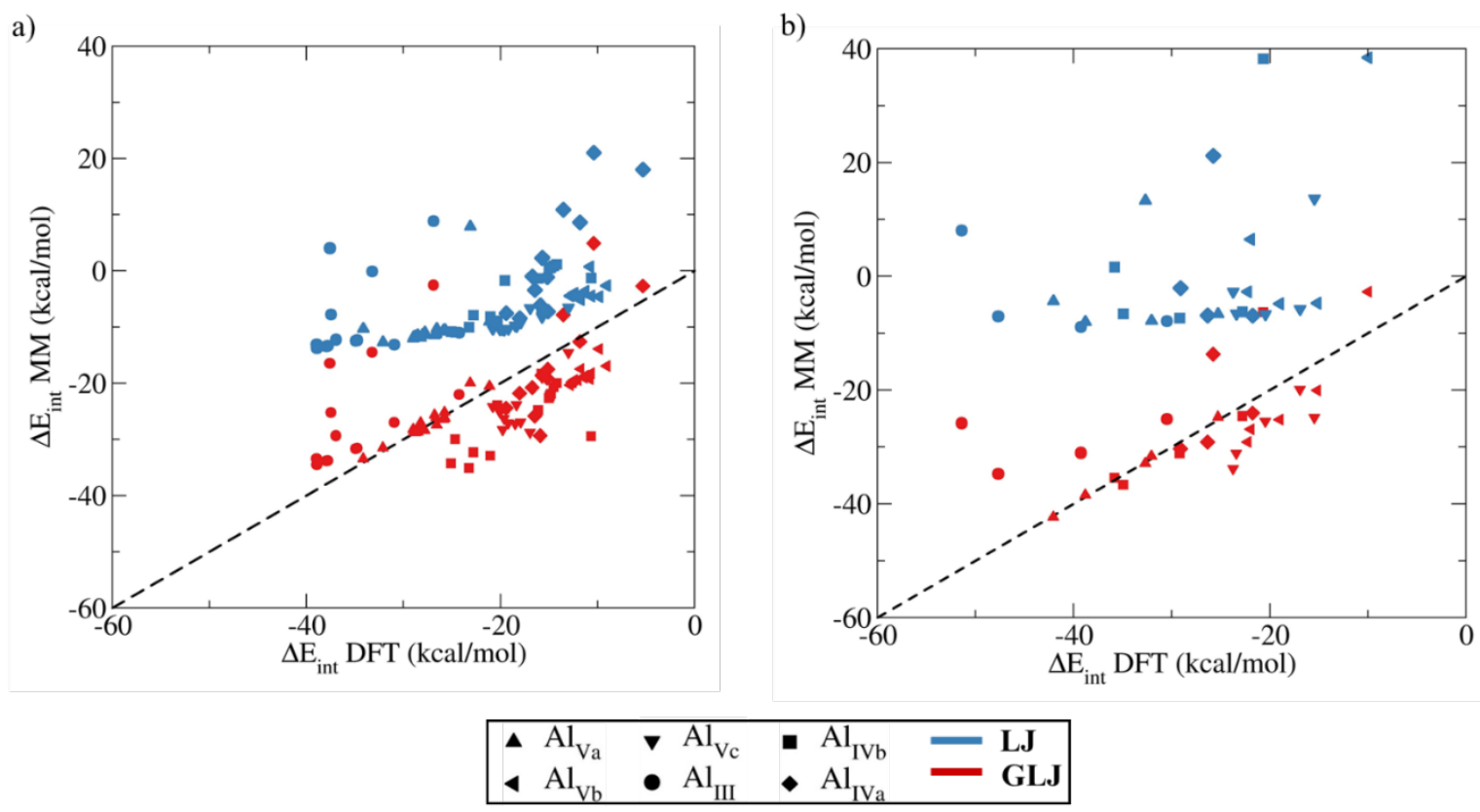

c)

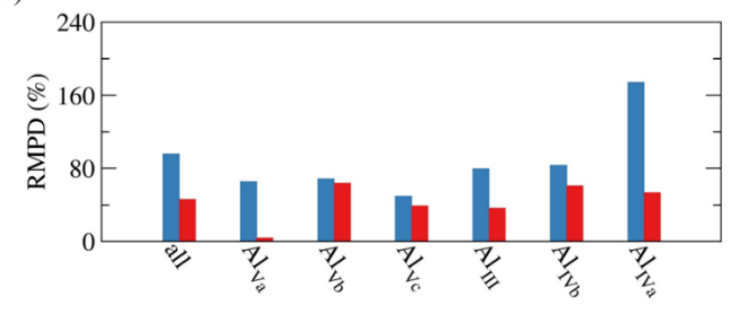

d)

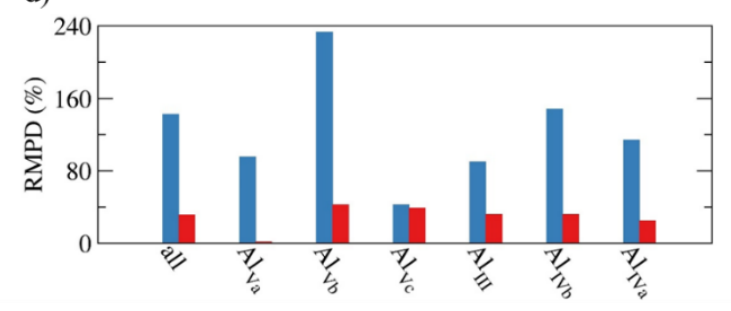

Figure 4. Comparison of interaction energies of (a) dimethyl ether $\left(\mathrm{Me}_{2} \mathrm{O}\right)$ and (b) dimethyl amine ( $\left.\mathrm{Me}_{2} \mathrm{NH}\right)$ on different Al sites computed with molecular mechanics (MM in blue and MM+g in red) and DFT. Corresponding RMPD bar plots (percentage) for dimethyl ether (c) and dimethyl amine (d).

Like over hematite, the $\mathrm{LJ}$ level is largely underbinding for $\mathrm{Me}_{2} \mathrm{O}$ and $\mathrm{Me}_{2} \mathrm{NH}$ (RMPD 100\%). Furthermore, LJ only leads to small difference between sites, in contrast to DFT. With the Gaussian attractive potential, the interactions computed at the GLJ level are stronger and thus much closer to the DFT values. Moreover, GLJ provides a better description of the diversity of the sites. The overall root mean square percentage deviation (RMPD) is improved from 95\% to $46 \%$ upon the inclusion of the attractive Gaussian potential, corresponding to an RMSD of 17.1 and $7.5 \mathrm{kcal} / \mathrm{mol}$ respectively.

Since the attractive Gaussian potential has been fitted on $\mathrm{Al}_{v_{v}}$, the improvement of GLJ over LJ is excellent for this site of the (100) surface (with a marked decrease of the RMPD from 65.4\% to $3.75 \%$ for dimethylether and $95.2 \%$ to $1.2 \%$ for dimethylamine). For the other sites of the (100) surface, which are less reactive, the attractive Gaussian potential is over-binding with respect to DFT, and the RMPD improvement is less important. The $\mathrm{Al}_{\Perp}$ site of the (110) surface 
is the most reactive site studied, significantly more than the $A l_{\text {va }}$ site used to fit the Gaussians parameters. LJ interaction energies are considerably improved but, as expected, the GLJ potential remains slightly under-binding near the $\mathrm{Al}_{\mathrm{m}}$ adsorption site (Figure 5. a) Interaction energies of dimethylether (carbon atom in blue, oxygen of dimethylether in red) with the $\gamma$ alumina (110) surface, explored by translation of the adsorbed dimethylether along $\mathrm{x}$ axis, starting from the $\mathrm{Al}_{\mathrm{I}}$ site.Figure 5). For the less reactive sites of the (110) surface, the RMPD decreases very significantly (see Table S4). In these cases, LJ potential is largely under-binding and GLJ becomes over-binding (see $\mathrm{Al}_{\mathrm{vv}}$ site on Figure 5.b).

a)

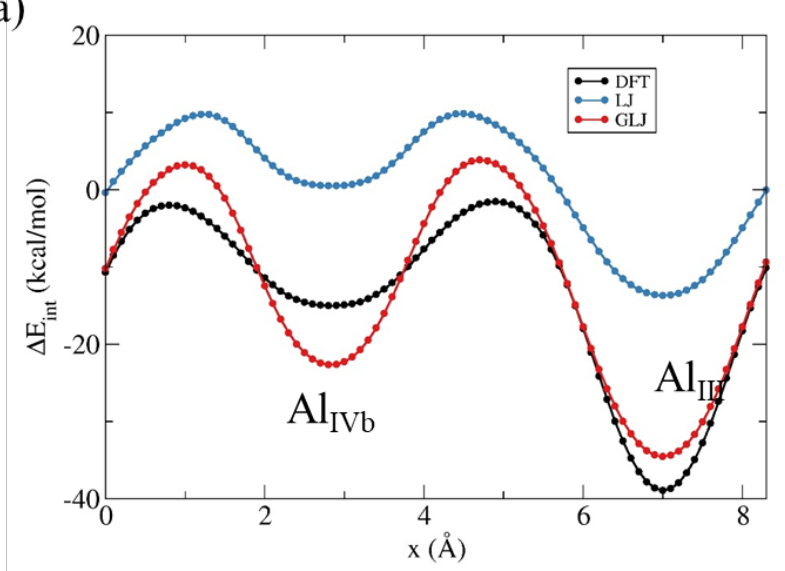

b)

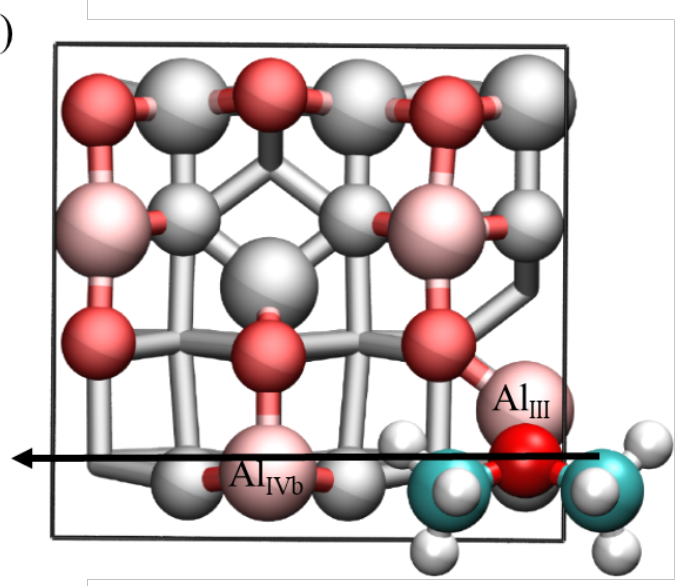

Figure 5. a) Interaction energies of dimethylether (carbon atom in blue, oxygen of dimethylether in red) with the $\gamma$-alumina (110) surface, explored by translation of the adsorbed dimethylether along $\mathrm{x}$ axis, starting from the $\mathrm{Al}_{\text {III }}$ site. b) The translation of dimethylether is shown with a black horizontal arrow.

As a conclusion, there is a good overall transferability of the Gaussian parameters between sites, considering that these sites are of different acidities and natures (different coordination of the aluminum atom, tri-, tetra- or penta-coordinated) and that the attractive Gaussian potential was adjusted on the $\mathrm{Al}_{\mathrm{va}}$ site only. Taking into account dimethylether and dimethylamines on all adsorption sites, the RMSD decreases significantly by adding the Gaussian potential from 21.5 to $7.6 \mathrm{kcal} / \mathrm{mol}$ and the RMPD from 109 to $43 \%$. In other words, with a minimal parametrization effort, the adsorption energy profiles are quantitatively improved for all sites of alumina surfaces.

\subsection{Transferability among sites and molecules on alumina surface}

In this section, we assess the transferability of the Gaussian parameters obtained for Al-O and Al-N using dimethyl ether and dimethylamine to other sites and other molecules. Like for hematite, we considered methanol, water and acetone for oxygenated molecules, methylamine, 
ammonia and trimethylamine for nitrogenated molecules. Interaction energies for these four molecules were computed on the six different adsorption sites of the (110) and (100) $\gamma$-alumina surfaces, at different altitudes above these sites, as explained in Section 2. As the transferability of the Gaussian parameters from one site to another has already been investigated in the previous section, we here focus only on the two most reactive sites $\left(A l_{\text {III }}\right.$ and $\left.A l_{v_{\mathrm{v}}}\right)$, while the results for the other sites are reported in Supporting Information (Figure S3 and Tables S8 and S9). In Figure 6, the resulting interaction energies obtained at the GLJ level are plotted against the DFT results together with the corresponding RMPD, whereas the LJ results are shown in Figure S2 and RMSD are given in Tables S6 and S7.

a)

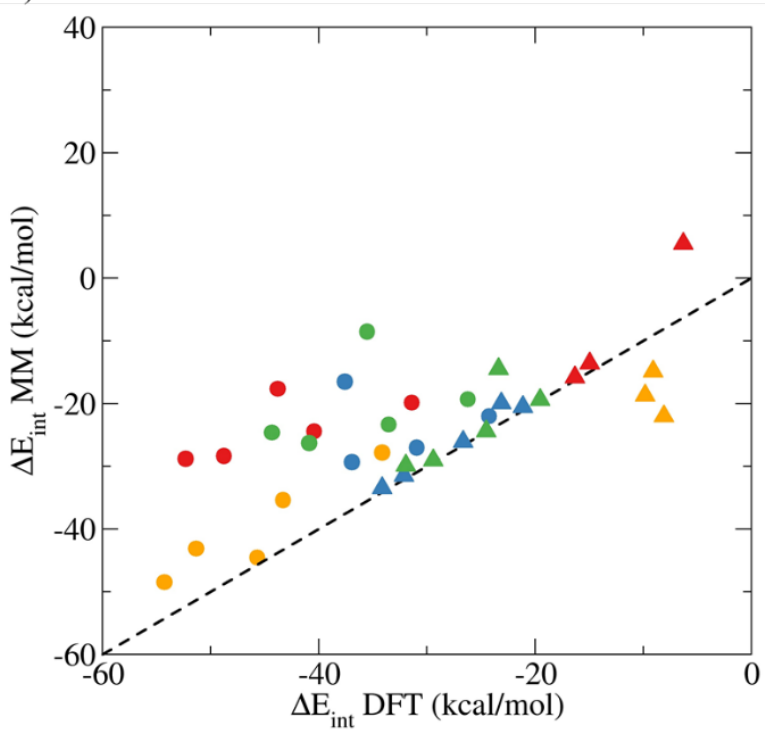

\begin{tabular}{|lllll|}
\hline $\mathrm{Me}_{2} \mathrm{O}$ & $\quad$ & $\mathrm{H}_{2} \mathrm{O}$ & $\boldsymbol{\Delta}$ & $\mathrm{Al}_{\mathrm{Va}}$ \\
$\mathrm{MeOH}$ & - & acetone & $\mathrm{Al}_{\text {III }}$ \\
\hline
\end{tabular}

c)

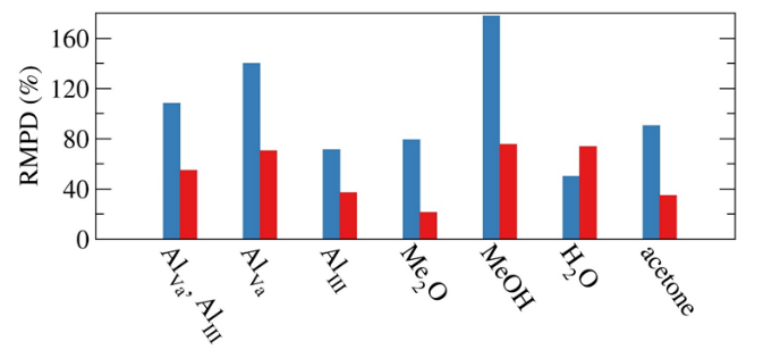

b)
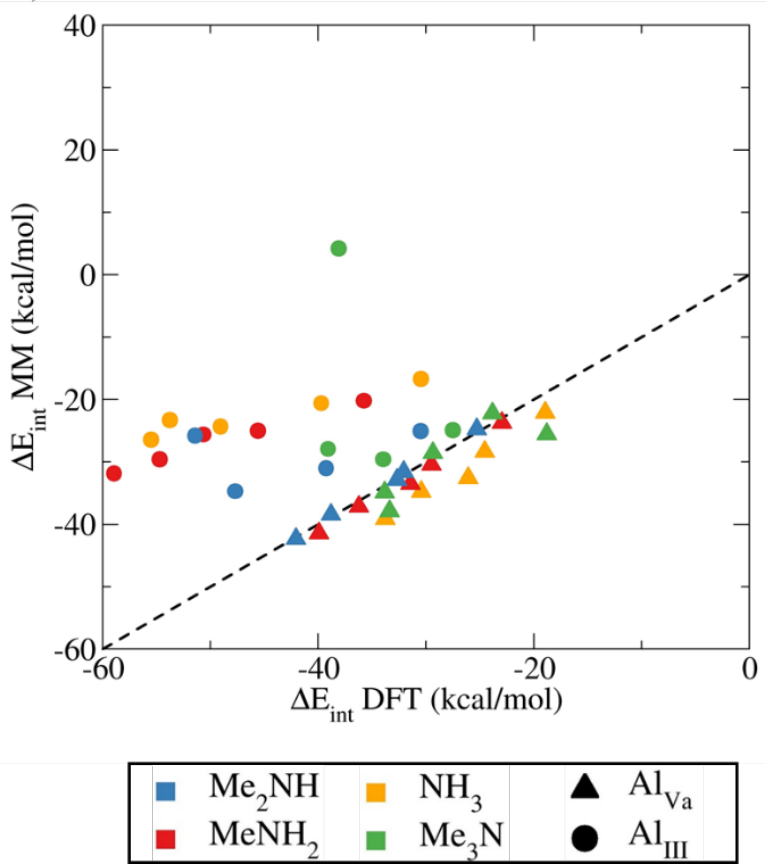

d)

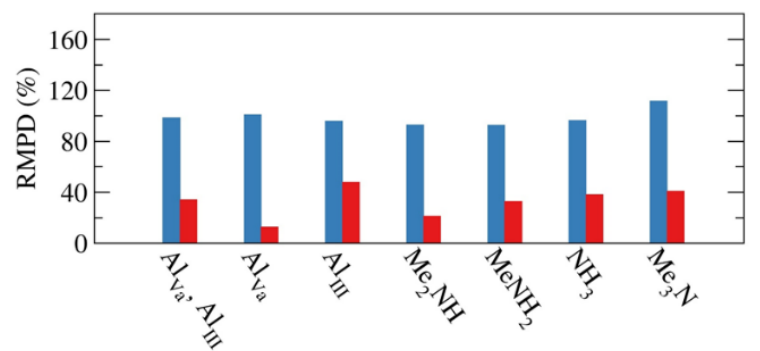

Figure 6. GLJ vs. DFT interaction energies of (a) oxygenated molecules (b) nitrogenated molecules on the most reactive Al site ( $\mathrm{Al}_{\text {III }}$, squares) and on the site originally used to fit the Gaussian (Alva, up triangles). Corresponding bar plots for (c) oxygenated and (d) nitrogenated molecules, in percentage, for all molecules on both sites (labeled all), for all molecules on each site ( $\mathrm{Al}_{\mathrm{Va}}$ and $\mathrm{Al}_{\mathrm{III}}$ ), and for each molecule on both sites.

In agreement with all observations above, LJ is largely underbinding compared to DFT for all molecules (see Figure S2). Computed interaction energies depend only very slightly of the 
nature of the molecule and of the site. They do not drop below $-20 \mathrm{kcal} / \mathrm{mol}$ for ethanol, dimethylether and acetone and below $-10 \mathrm{kcal} / \mathrm{mol}$ for nitrogenated molecules. With GLJ, the $A l-O$ or $A l-N$ interaction is stronger and the interaction of oxygenated (except water) and nitrogenated molecules is now consistent with DFT results on $\mathrm{Al}_{\mathrm{va}}$. For example, the RMPD for amines decreases from $100.7 \%$ to $12.7 \%$ and RMSD from 30.0 to $3.1 \mathrm{kcal} / \mathrm{mol}$.

This again demonstrates the very good transferability from one molecule to the next of the Gaussian parameters. Noticeably, the water molecule appears here as an exception with a RMPD that is not improved by the inclusion of the attractive Gaussian potential. This can be related to the weak interaction of water with the $\mathrm{Al}_{\mathrm{va}_{\mathrm{a}}}$ site. $\mathrm{LJ}$ is slightly underbinding whereas GLJ is slightly overbinding with respect to DFT. With interaction energies close to zero at the DFT level, artificially large RMPD (73.5\% on both sites at the GLJ level) are obtained while RMSD values in $\mathrm{kcal} / \mathrm{mol}$ decrease (from 14.5 to $8.0 \mathrm{kcal} / \mathrm{mol}$, see Table S6).

The interaction of the set of molecules with the more acidic $\mathrm{Al}_{\mathrm{m}}$ site is even more demanding since it relies on a combined transferability to a more acidic site and to another molecule. As expected, given the stronger acidity of $\mathrm{Al}_{\mathbb{m}}$, the GLJ interaction of these molecules is still underbinding. Importantly, the global RMSD decreases very significantly from 28.2 to 14.9 $\mathrm{kcal} / \mathrm{mol}$ and so does the RMPD from 71.3 to $36.8 \%$.

All in all, the transferability of the GLJ parameters fitted on dimethylether or dimethylamine on the $\mathrm{Al}_{\mathrm{va}}$ site to the $\mathrm{Al}_{\mathrm{II}}$ site and to other molecules is satisfactory. Taking into account all molecules and all adsorption sites (Table S8 and S9), the RMSD decreases significantly by adding the Gaussian potential from 23.7 to $11.1 \mathrm{kcal} / \mathrm{mol}$ (Table S10).

In other words, without any supplementary parametrization, the attractive Gaussian potential fitted on the interaction of dimethylether or dimethylamine on the $\mathrm{Al}_{\mathrm{va}_{\mathrm{a}}}$ site of the (100) surface can improve the MM description of the interaction of various oxygenated or nitrogenated molecules on (110) and (100) $\gamma$-alumina surfaces.

\section{Film structuration}

In this section we analyze the impact of the attractive Gaussian potential on the structuration of molecular films comparing LJ and GLJ. These molecular films are important in a variety of application, from tribology to corrosion. ${ }^{92-4}$ Typically, fatty amines are used as lubrication additives to beneficiate from their anti-corrosion and friction modification abilities.

We consider here two systems of increasing complexity: (i) an aliphatic primary amine film 
on hematite and (ii) a surfactant with a mixed $\mathrm{N}$ - and $\mathrm{O}-$ polyfunctional head, $\mathrm{N}$ tetradecyldiethanolamine, which can form a film on (100) $\gamma$-alumina (see Figure 7.a and Figure $7 . b$ respectively).

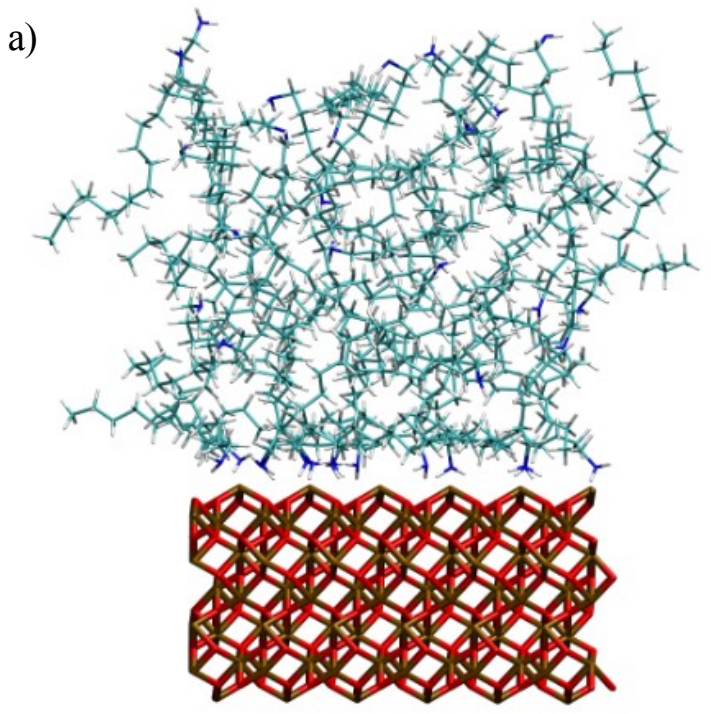

b)

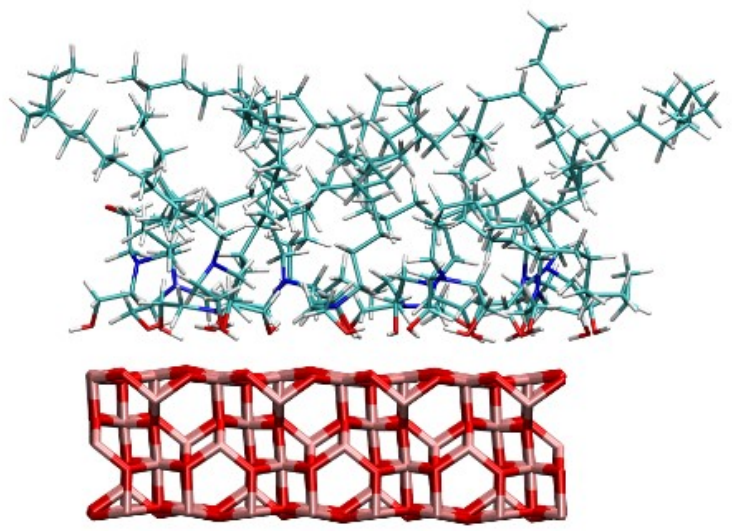

Figure 7. Snapshots of the two systems studied as applications: (a) 36 molecules of n-octadecanamine on the (0001) surface of hematite and (b) 12 molecules of $N$-tetradecyldiethanolamine on the (100) surface of $\gamma$-alumina (Fe in brown, $\mathrm{Al}$ in pink, $\mathrm{O}$ in red, $\mathrm{N}$ in blue, $\mathrm{H}$ in white and $\mathrm{C}$ in cyan).

\section{1. n-octadecanamine $\mathrm{C}_{18} \mathrm{H}_{37} \mathrm{NH}_{2}$ on hematite}

To study the structural properties of the n-octadecanamine film on hematite and the differences between LJ and GLJ, the average surface concentration of nitrogen atoms is plotted as a function of the distance to the surface in Figure 8. Remarkably, independent on the force field, after the equilibration around 12 nitrogen atoms are clearly located near the surface while the 36 n-octadecanamine molecules were initially randomly distributed. This adsorption mode, where the nitrogen atoms are linked to the iron atoms of the surface, is in agreement with theoretical and experimental data available the literature..$^{9596}$

By comparing the two curves on Figure 8, it can nevertheless be seen that these nitrogen atoms are located closer to the surface when using GLJ than LJ: $1.4 \AA$ vs. $2.2 \AA$ perpendicularly to the surface. This corresponds to an average distance between the nitrogen atoms and their adsorption site of 2.1 and $2.6 \AA$, respectively, as they are not adsorbed exactly on top of the surface iron atoms. DFT calculations have shown that the adsorption of a primary amine over hematite leads to an Fe-N distance of $2.12 \AA$ A, demonstrating that GLJ calculations are more realistic than LJ. The corresponding peak is also much sharper indicating a stronger localization closer to the surface. As indicated by the near-linear increase in the integral, the remaining 24 nitrogen atoms are quite evenly distributed across the film. 
To investigate the film structuring parallel to the surface, the surface concentration of nitrogen atom is averaged over a $5 \AA$ thick slab above the hematite surface (Figure 9. Concentration of nitrogen atoms (in $\AA^{-3}$ ) within the first $5 \AA$ above the surface in the xy plane during the (a) LJ and (b) GLJ simulations. Black crosses represent the position of the surface iron atoms corresponding to potential adsorption sites and dotted lines the boundaries of the periodic cell.). This structural characteristic is also clearly modified by the inclusion of an attractive gaussian potential. When using LJ, the n-octadecanamine molecules are diffusing freely, with only a small (the scale differs between panel $a$ and $b$ ) tendency of nitrogenated heads to cluster together. The slight heterogeneity that is observed cannot be related to the underlying surface structure and is expected to completely disappear with a longer averaging. In contrast, the 12 nitrogenated heads identified in the first peak of the density profile are clearly localized when using GLJ and are always found in a proximity of a Fe site. Literature results ${ }^{95}$ show a localisation of nitrogen atoms over the hematite surface very similar to the one obtained with our GLJ force field. This confirms, therefore, that a better description of the interface is achieved by the addition of attractive Gaussian potentials in comparison to LJ. 


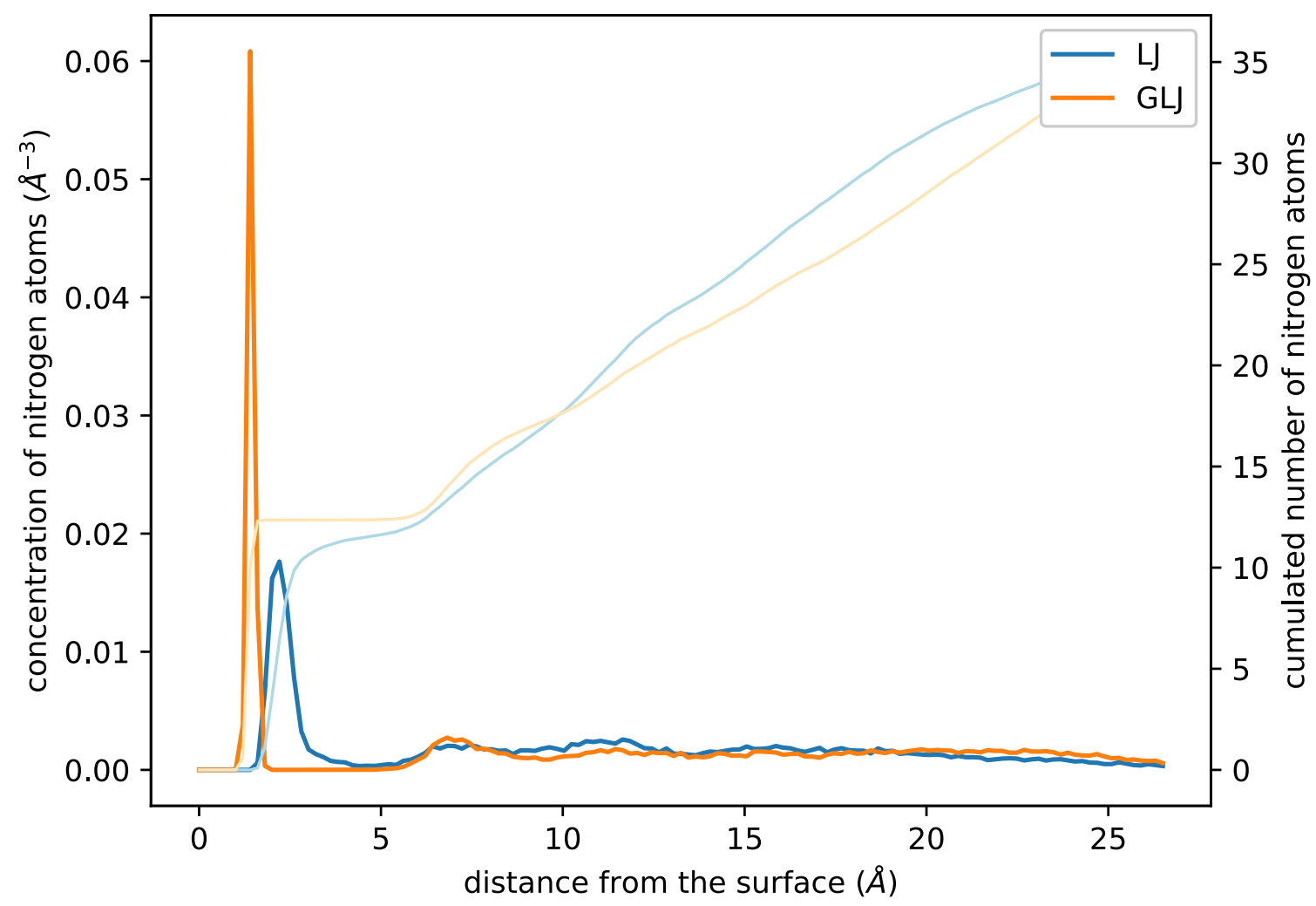

Figure 8. Concentration of nitrogen atoms as a function of the distance to the hematite surface using $\mathbf{L J}$ (in blue) and GLJ (in orange) potential in the molecular dynamics simulations. The corresponding cumulated number of nitrogen atoms is shown with a thin line.
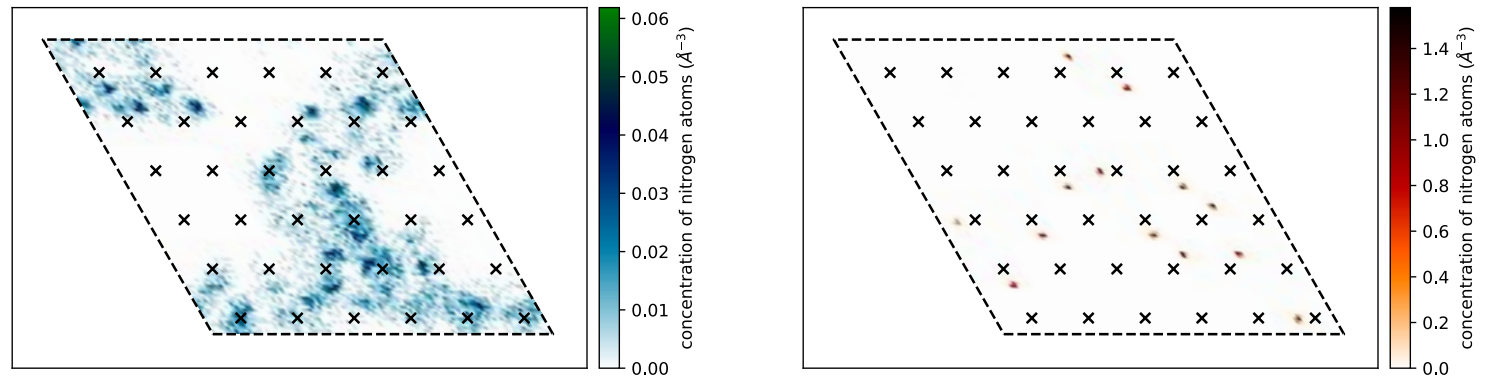

Figure 9. Concentration of nitrogen atoms (in $\AA^{-3}$ ) within the first $5 \AA$ above the surface in the xy plane during the (a) LJ and (b) GLJ simulations. Black crosses represent the position of the surface iron atoms corresponding to potential adsorption sites and dotted lines the boundaries of the periodic cell.

\subsection{Long chain ethoxylated amines on y-alumina (100) surface}

As a second test case with increased complexity, we investigated a polydentate head surfactant film made of $12 \mathrm{~N}$-tetradecyldiethanolamine molecules over the $\gamma$-alumina (100) surface, which exhibits various adsorption sites. Here again, LJ yields to a much less structured film 
than GLJ according to the density profile (Figure 10) and the surface concentration in the first $6 \AA$ (see Figure 11 and 12). The significant difference in structuration of the surface film could be responsible for misleading predictions of its properties.

From the surface concentration profile shown in Figure 10, it can be seen that Ntetradecyldiethanolamine binds to the surface by its oxygen atoms more likely than by its nitrogen atom. Indeed, oxygen atoms are in average closer ( $2.4 \AA$ for LJ and $2.0 \AA$ for GLJ) to the surface than nitrogen atoms (4.4 $\AA$ for LJ and $4.2 \AA$ for GLJ). Importantly, the peak for oxygen integrates for 23 using GLJ and only 19 using LJ (below $4 \AA$ ). The structure of the nitrogen peak is also of interest. While it is rather wide with no noticeable structuration when using LJ, it splits into several peaks, the first small one is positioned at $2.6 \AA$ and integrates for 0.6 atoms when using GLJ. In other words, the inclusion of a differentiated attractive gaussian for the Al-O and Al-N interaction allows the nitrogen atom to interact more closely with the surface. All nitrogen atoms are found in a $6 \AA$ slab independent on the presence of the Gaussian attraction.

The structuration within this $6 \AA$ slab in term of oxygen and nitrogen atom concentration is provided in Figure 11 and 12 respectively. Like the previous case, the head of the surfactant is much less localized when using LJ vs. GLJ. In addition, their localization differs. When using $\mathrm{LJ}$, the 21 oxygen atoms tend to be in the vicinity of $\mathrm{Al}_{\mathrm{va}}$ and $\mathrm{Al} \mathrm{v}_{\mathrm{vc}}$ while the 11 nitrogen atoms are preferentially found in between $\mathrm{Al}$ sites. When switching on the gaussian attractive potential moving to GLJ, 23 oxygen atoms can also be found in close interaction with the Al sites, the $\mathrm{Al}_{\mathrm{vb}}$ site included. Furthermore, the 12 nitrogen atoms are also more localized, three of them are even on top of an $\mathrm{Al}_{\mathrm{va}_{\mathrm{a}}}$ or $\mathrm{Al}_{\mathrm{vc}}$ site. All in all, the molecules are more likely adsorbed on $\mathrm{Al}_{\mathrm{va}_{\mathrm{a}}}$ and $\mathrm{Al}_{\mathrm{vc}}$ atoms of the surface, which is coherent with the fact that $\mathrm{Al}_{\mathrm{va}_{\mathrm{a}}}$ is the most acidic and therefore the most reactive aluminum atom of the (100) $\gamma$-alumina surface. 


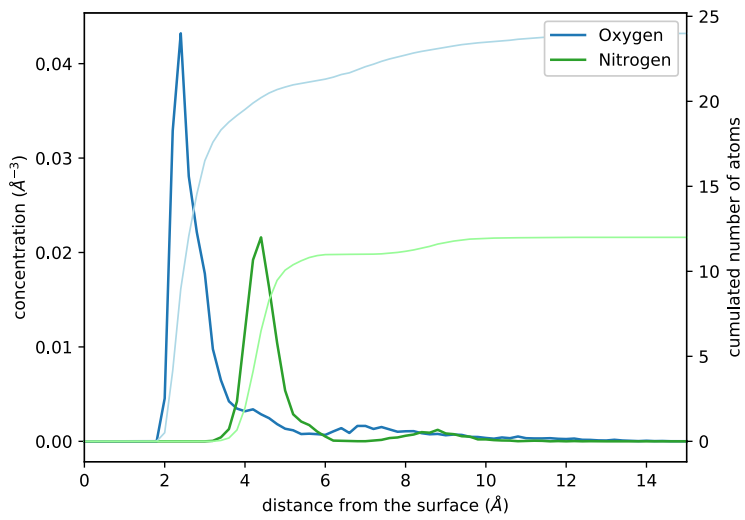

b)

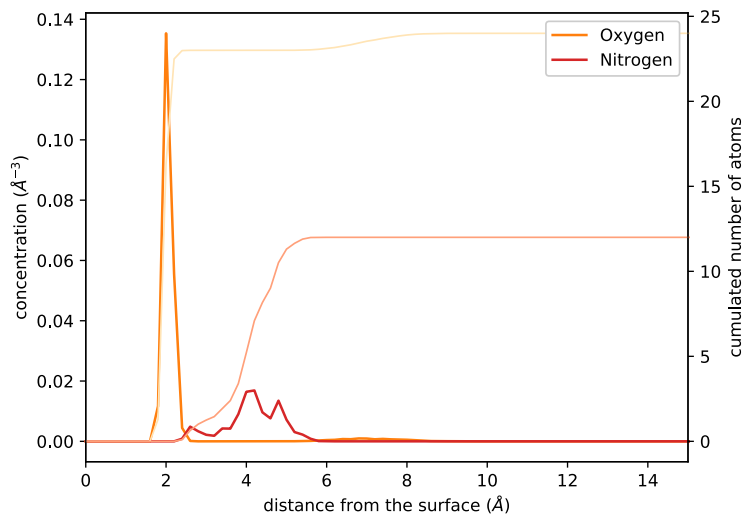

Figure 10. Concentration of oxygen and nitrogen atoms as a function of the distance to the surface during the (a) LJ and (b) GLJ simulations. The corresponding cumulated number of nitrogen or oxygen atoms in is shown with a thin line.

a)

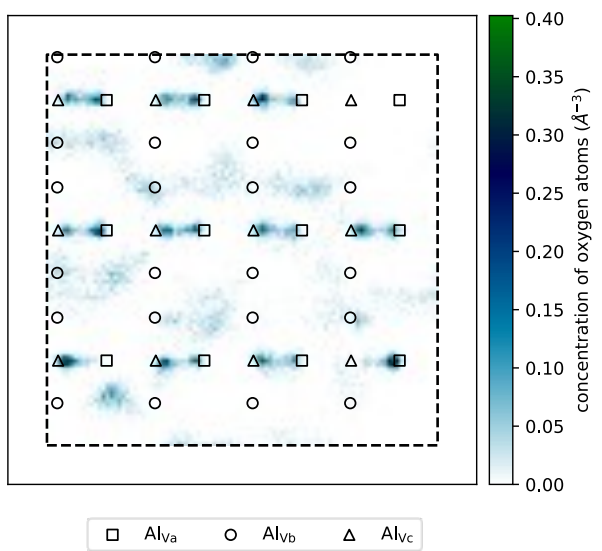

b)

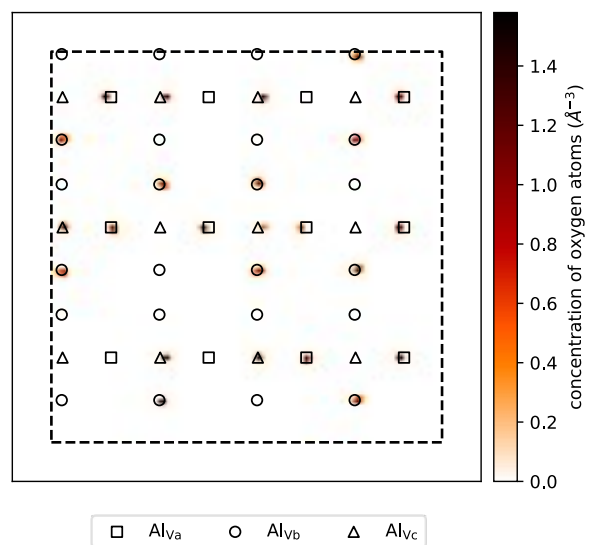

Figure 11. Concentration of oxygen atoms within the first $6 \AA$ above the surface in the xy plane during the (a) LJ and (b) GLJ simulations. Squares, circles and triangles represent the position of the surface aluminum atoms corresponding to $\mathrm{Al}_{\mathrm{Va}}, \mathrm{Al}_{\mathrm{vb}}$ and $\mathrm{Al}_{\mathrm{vc}}$ respectively and dotted lines the boundaries of the periodic cell. 
a)

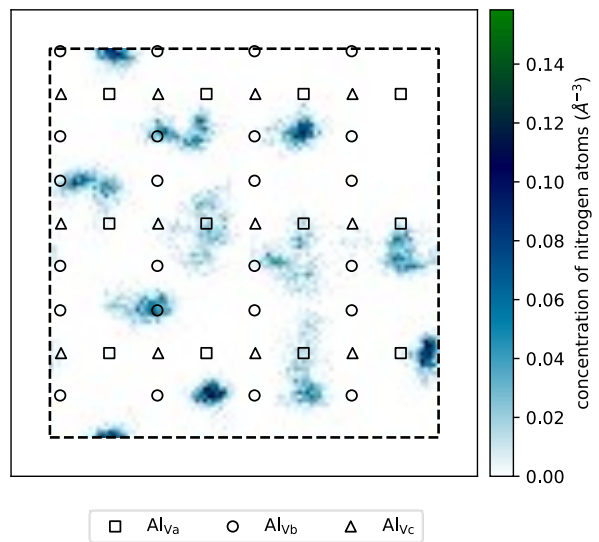

b)

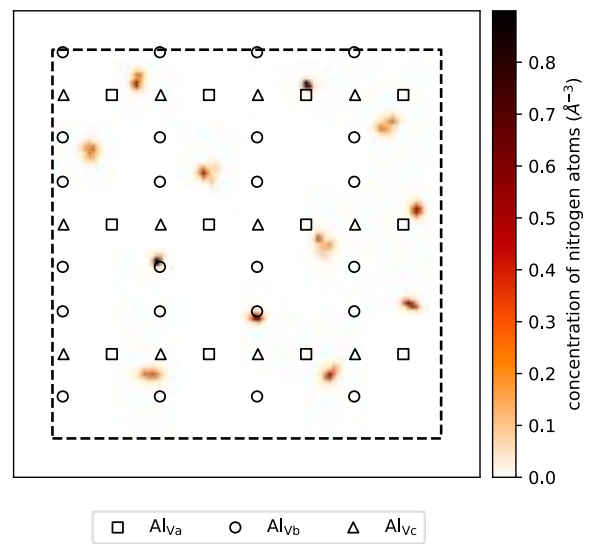

Figure 12. Concentration of nitrogen atoms within the first $6 \AA$ above the surface in the $x y$ plane during the (a) LJ and (b) GLJ simulations. Squares, circles and triangles represent the position of the surface aluminum atoms corresponding to $\mathrm{Al}_{\mathrm{Va}}, \mathrm{Al}_{\mathrm{vb}}$ and $\mathrm{Al}_{\mathrm{vc}}$ respectively and dotted lines the boundaries of the periodic cell.

\section{CONCLUSION}

We herein propose a fast and easy to implement improvement of the usual pairwise additive force fields used for surface/molecules interactions. An attractive Gaussian potential is added to the Lennard-Jones potential (GLJ level of theory). The three parameters for a metalheteroatom interaction were fitted for a typical molecule and a typical surface site and the transferability to other sites and other molecules was extensively tested on two protypical surfaces, hematite and $\gamma$-alumina. On hematite, with a single reactive site, the GLJ results are considerably improved when compared to LJ. The transferability between oxygenated and nitrogenated molecules of the same family leads to a significant improvement: the total RMSD for all probed molecules decreases from 29.2 to $5.7 \mathrm{kcal} / \mathrm{mol}$, and the corresponding percentage from 107.4 to $22.6 \%$. On $\gamma$-alumina, we show that there is a good transferability for the adsorption of dimethylether or dimethylamine fitted on $\mathrm{Al}_{\mathrm{v}_{\mathrm{a}}}$ site to other surface sites (RMSD decreases from 23.7 to $11.1 \mathrm{kcal} / \mathrm{mol}$ ) and also for our two series of oxygenated and nitrogenated molecules on different sites (RMSD decreases from 21.5 to $7.6 \mathrm{kcal} / \mathrm{mol}$ ). This improved simple GLJ potential proves useful in the simulation of n-octadecanamine and $\mathrm{N}$ tetradecyldiethanolamine adsorbed films on hematite and alumina respectively. Indeed, the GLJ potential shows a much stronger structuration and slower dynamics of the surface films, in agreement with the adsorption energies determined by first principles computations for model head-groups. 


\section{ACKNOWLEDGMENTS}

This work is part of the project IDEXLYON funded by the French National Research Agency (ANR-16-IDEX-0005), the Commissariat-General for Investment (CGI) and awarded of M€25 (for 4 years) by the French Government within the framework of the Investissements d'Avenir program ("Investment for the Futur"). S. B. gratefully acknowledges Total MS and the ANRT for her PhD fellowship. The authors thank the SYSPROD project and AXELERA Pôle de Compétitivité for financial support (PSMN Data Center).

\section{SUPPORTING INFORMATION}

Supporting information includes complementary figures and tables, the coordinates of optimal geometries of the chemisorbed molecules and of one snapshot of the two interfaces. Coordinates along the molecular dynamics trajectory for the films are provided as zip archive. 


\section{BIBLIOGRAPHY}

(1) Sievers, C.; Noda, Y.; Qi, L.; Albuquerque, E. M.; Rioux, R. M.; Scott, S. L. Phenomena Affecting Catalytic Reactions at Solid-Liquid Interfaces. ACS Catal. 2016, 6 (12), 82868307. https://doi.org/10.1021/acscatal.6b02532.

(2) Romo, J. E.; Bollar, N. V.; Zimmermann, C. J.; Wettstein, S. G. Conversion of Sugars and Biomass to Furans Using Heterogeneous Catalysts in Biphasic Solvent Systems. ChemCatChem 2018, 10 (21), 4805-4816. https://doi.org/10.1002/cctc.201800926.

(3) Xu, S.; Carter, E. A. Theoretical Insights into Heterogeneous (Photo)Electrochemical CO Reduction. Chem. Rev. 2019, 119 (11), 6631-6669. https://doi.org/10.1021/acs.chemrev.8b00481.

(4) Garley, A.; Hoff, S. E.; Saikia, N.; Jamadagni, S.; Baig, A.; Heinz, H. Adsorption and Substitution of Metal Ions on Hydroxyapatite as a Function of Crystal Facet and Electrolyte PH. J. Phys. Chem. C 2019, 123 (27), 16982-16993. https://doi.org/10.1021/acs.jpcc.9b02808.

(5) Feng, J.; Pandey, R. B.; Berry, R. J.; Farmer, B. L.; Naik, R. R.; Heinz, H. Adsorption Mechanism of Single Amino Acid and Surfactant Molecules to Au \{111\} Surfaces in Aqueous Solution: Design Rules for Metal-Binding Molecules. Soft Matter 2011, 7 (5), 2113. https://doi.org/10.1039/c0sm01118e.

(6) Wright, L. B.; Rodger, P. M.; Corni, S.; Walsh, T. R. GolP-CHARMM: First-Principles Based Force Fields for the Interaction of Proteins with $\mathrm{Au}(111)$ and $\mathrm{Au}(100)$. J. Chem. Theory Comput. 2013, 9 (3), 1616-1630. https://doi.org/10.1021/ct301018m.

(7) Brandt, E. G.; Lyubartsev, A. P. Molecular Dynamics Simulations of Adsorption of Amino Acid Side Chain Analogues and a Titanium Binding Peptide on the $\mathrm{TiO}_{2}(100)$ Surface. J. Phys. Chem. C 2015, 119 (32), 18126-18139. https://doi.org/10.1021/acs.jpcc.5b02670.

(8) Ruan, M.; Seydou, M.; Noel, V.; Piro, B.; Maurel, F.; Barbault, F. Molecular Dynamics Simulation of a RNA Aptasensor. J. Phys. Chem. B 2017, 121 (16), 4071-4080. https://doi.org/10.1021/acs.jpcb.6b12544.

(9) Jiang, W.; Pan, H.; Zhang, Z.; Qiu, S. R.; Kim, J. D.; Xu, X.; Tang, R. Switchable Chiral Selection of Aspartic Acids by Dynamic States of Brushite. J. Am. Chem. Soc. 2017, 139 (25), 8562-8569. https://doi.org/10.1021/jacs.7b03116.

(10) Pham, T. T.; Lemaire, T.; Capiez-Lernout, E.; Lewerenz, M.; To, Q.-D.; Christie, J. K.; Di Tommaso, D.; de Leeuw, N. H.; Naili, S. Properties of Water Confined in Hydroxyapatite Nanopores as Derived from Molecular Dynamics Simulations. Theor. Chem. Acc. 2015, 134 (5), 59. https://doi.org/10.1007/s00214-015-1653-3.

(11) Garcia, N.; Raiteri, P.; Vlieg, E.; Gale, J. Water Structure, Dynamics and Ion Adsorption at the Aqueous $\{010\}$ Brushite Surface. Minerals 2018, 8 (8), 334. https://doi.org/10.3390/min8080334.

(12) Brugger, J.; Liu, W.; Etschmann, B.; Mei, Y.; Sherman, D. M.; Testemale, D. A Review of the Coordination Chemistry of Hydrothermal Systems, or Do Coordination Changes Make Ore Deposits? Chem. Geol. 2016, 447, 219-253. https://doi.org/10.1016/j.chemgeo.2016.10.021.

(13) Thompson, W. H. Perspective: Dynamics of Confined Liquids. J. Chem. Phys. 2018, 149 (17), 170901. https://doi.org/10.1063/1.5057759.

(14) Maurice, V.; Marcus, P. Progress in Corrosion Science at Atomic and Nanometric Scales. Prog. Mater. Sci. 2018, 95, 132-171. https://doi.org/10.1016/j.pmatsci.2018.03.001.

(15) Berro, H. Molecular Dynamics Simulation of Surface Energy and ZDDP Effects on Friction in Nano-Scale Lubricated Contacts. Tribol. Int. 2010, 12. 
(16) Apóstolo, R. F. G.; Tsagkaropoulou, G.; Camp, P. J. Molecular Adsorption, SelfAssembly, and Friction in Lubricants. J. Mol. Liq. 2019, 277, 606-612. https://doi.org/10.1016/j.molliq.2018.12.099.

(17) Parkinson, G. S. Iron Oxide Surfaces. Surf. Sci. Rep. 2016, 71 (1), 272-365. https://doi.org/10.1016/j.surfrep.2016.02.001.

(18) Digne, M.; Sautet, P.; Raybaud, P.; Euzen, P.; Toulhoat, H. Use of DFT to Achieve a Rational Understanding of Acid-Basic Properties of $\gamma$-Alumina Surfaces. J. Catal. 2004, 226 (1), 54-68. https://doi.org/10.1016/j.jcat.2004.04.020.

(19) Rollmann, G.; Rohrbach, A.; Entel, P.; Hafner, J. First-Principles Calculation of the Structure and Magnetic Phases of Hematite. Phys. Rev. B 2004, 69 (16), 165107. https://doi.org/10.1103/PhysRevB.69.165107.

(20) Chia, C.-L.; Avendaño, C.; Siperstein, F. R.; Filip, S. Liquid Adsorption of Organic Compounds on Hematite $\alpha-\mathrm{Fe}_{2} \mathrm{O}_{3}$ Using ReaxFF. Langmuir 2017, 33 (42), 1125711263. https://doi.org/10.1021/acs.langmuir.7b02374.

(21) Shrimali, K.; Jin, J.; Hassas, B. V.; Wang, X.; Miller, J. D. The Surface State of Hematite and Its Wetting Characteristics. J. Colloid Interface Sci. 2016, 477, 16-24. https://doi.org/10.1016/j.jcis.2016.05.030.

(22) Lane, J. M. D.; Leung, K.; Thompson, A. P.; Cuneo, M. E. Water Desorption from Rapidly-Heated Metal Oxide Surfaces-First Principles, Molecular Dynamics, and the Temkin Isotherm. J. Phys. Condens. Matter 2018, 30 (46), 465002. https://doi.org/10.1088/1361-648X/aae4af.

(23) Foucaud, Y.; Badawi, M.; Filippov, L.; Filippova, I.; Lebègue, S. A Review of Atomistic Simulation Methods for Surface Physical-Chemistry Phenomena Applied to Froth $\begin{array}{lllll}\text { Flotation. } & \text { Miner. } & \text { Eng. } & 106020 .\end{array}$ https://doi.org/10.1016/j.mineng.2019.106020.

(24) Sivula, K.; Le Formal, F.; Grätzel, M. Solar Water Splitting: Progress Using Hematite ( $\alpha$ Fe2O3) Photoelectrodes. ChemSusChem 2011, 4 (4), 432-449. https://doi.org/10.1002/cssc.201000416.

(25) Euzen, P.; Raybaud, P.; Krokidis, X.; Toulhoat, H.; Le Loarer, J.-L.; Jolivet, J.-P.; Froidefond, C. Alumina. In Handbook of Porous Solids; Schth, F., Sing, K. S. W., Weitkamp, J., Eds.; Wiley-VCH Verlag GmbH: Weinheim, Germany, 2002; pp 15911677. https://doi.org/10.1002/9783527618286.ch23b.

(26) Copeland, J. R.; Shi, X.-R.; Sholl, D. S.; Sievers, C. Surface Interactions of C2 and C3 Polyols with $\gamma$-Al2O3 and the Role of Coadsorbed Water. Langmuir 2013, 29 (2), 581593. https://doi.org/10.1021/la304074x.

(27) Réocreux, R.; Girel, É.; Clabaut, P.; Tuel, A.; Besson, M.; Chaumonnot, A.; Cabiac, A.; Sautet, P.; Michel, C. Reactivity of Shape-Controlled Crystals and Metadynamics Simulations Locate the Weak Spots of Alumina in Water. Nat. Commun. 2019, 10 (1), 3139. https://doi.org/10.1038/s41467-019-10981-9.

(28) Ngouana-Wakou, B. F.; Cornette, P.; Corral Valero, M.; Costa, D.; Raybaud, P. An Atomistic Description of the $\gamma$-Alumina/Water Interface Revealed by Ab Initio Molecular Dynamics. J. Phys. Chem. C 2017, 121 (19), 10351-10363. https://doi.org/10.1021/acs.jpcc.7b00101.

(29) Blanck, S.; Loehlé, S.; Steinmann, S. N.; Michel, C. Adhesion of Lubricant on Aluminium through Adsorption of Additive Head-Groups on $\gamma$-Alumina: A DFT Study. Tribol. Int. 2020, 145, 106140. https://doi.org/10.1016/j.triboint.2019.106140.

(30) Réocreux, R.; Jiang, T.; Iannuzzi, M.; Michel, C.; Sautet, P. Structuration and Dynamics of Interfacial Liquid Water at Hydrated $\gamma$-Alumina Determined by Ab Initio Molecular Simulations: Implications for Nanoparticle Stability. ACS Appl. Nano Mater. 2018, 1 (1), 191-199. https://doi.org/10.1021/acsanm.7b00100. 
(31) von Rudorff, G. F.; Jakobsen, R.; Rosso, K. M.; Blumberger, J. Hematite(001)-Liquid Water Interface from Hybrid Density Functional-Based Molecular Dynamics. J. Phys. Condens. Matter 2016, 28 (39), 394001. https://doi.org/10.1088/09538984/28/39/394001.

(32) Motta, A.; Gaigeot, M.-P.; Costa, D. AIMD Evidence of Inner Sphere Adsorption of Glycine on a Stepped (101) Boehmite AlOOH Surface. J. Phys. Chem. C 2012, 116 (44), 23418-23427. https://doi.org/10.1021/jp307565p.

(33) Heinz, H.; Vaia, R. A.; Farmer, B. L.; Naik, R. R. Accurate Simulation of Surfaces and Interfaces of Face-Centered Cubic Metals Using 12-6 and 9-6 Lennard-Jones Potentials. J. Phys. Chem. C 2008, 112 (44), 17281-17290. https://doi.org/10.1021/jp801931d.

(34) Heinz, H.; Lin, T. J.; Mishra, R. K.; Emami, F. S. Thermodynamically Consistent Force Fields for the Assembly of Inorganic, Organic, and Biological Nanostructures: The INTERFACE Force Field. Langmuir 2012, 29 (6), 1754-1765. https://doi.org/10.1021/la3038846.

(35) Cygan, R. T.; Liang, J.-J.; Kalinichev, A. G. Molecular Models of Hydroxide, Oxyhydroxide, and Clay Phases and the Development of a General Force Field. J. Phys. Chem. B 2004, 108 (4), 1255-1266. https://doi.org/10.1021/jp0363287.

(36) Argyris, D.; Ho, T.; Cole, D. R.; Striolo, A. Molecular Dynamics Studies of Interfacial Water at the Alumina Surface. J. Phys. Chem. C 2011, 115 (5), 2038-2046. https://doi.org/10.1021/jp109244c.

(37) Phan, A.; Cole, D. R.; Striolo, A. Liquid Ethanol Simulated on Crystalline Alpha Alumina. J. Phys. Chem. B 2013, 117 (14), 3829-3840. https://doi.org/10.1021/jp312238d.

(38) Soni, A.; Patey, G. N. Why $\alpha$-Alumina Is an Effective Ice Nucleus. J. Phys. Chem. C 2019, 123 (43), 26424-26431. https://doi.org/10.1021/acs.jpcc.9b07973.

(39) Xie, W. K.; Sun, Y. Z.; Liu, H. T. Atomistic Investigation on the Detachment of Oil Molecules from Defective Alumina Surface. Appl. Surf. Sci. 2017, 426, 504-513. https://doi.org/10.1016/j.apsusc.2017.07.163.

(40) Kerisit, S. Water Structure at Hematite-Water Interfaces. Geochim. Cosmochim. Acta 2011, 75 (8), 2043-2061. https://doi.org/10.1016/j.gca.2011.01.026.

(41) Boily, J.-F.; Yeşilbaş, M.; Md. Musleh Uddin, M.; Baiqing, L.; Trushkina, Y.; SalazarAlvarez, G. Thin Water Films at Multifaceted Hematite Particle Surfaces. Langmuir 2015, 31 (48), 13127-13137. https://doi.org/10.1021/acs.langmuir.5b03167.

(42) Olsen, R.; Leirvik, K. N.; Kvamme, B. Adsorption Characteristics of Glycols on Calcite and Hematite. AIChE J. 2019, 65 (11). https://doi.org/10.1002/aic.16728.

(43) Dzade, N.; Roldan, A.; de Leeuw, N. A Density Functional Theory Study of the Adsorption of Benzene on Hematite ( $\alpha$-Fe2O3) Surfaces. Minerals 2014, 4 (1), 89-115. https://doi.org/10.3390/min4010089.

(44) Gattinoni, C.; Ewen, J. P.; Dini, D. Adsorption of Surfactants on $\alpha-\mathrm{Fe}_{2} \mathrm{O}_{3}$ (0001): A Density Functional Theory Study. J. Phys. Chem. C 2018, 122 (36), 20817-20826. https://doi.org/10.1021/acs.jpcc.8b05899.

(45) Arrouvel, C.; Diawara, B.; Costa, D.; Marcus, P. DFT Periodic Study of the Adsorption of Glycine on the Anhydrous and Hydroxylated (0001) Surfaces of $\alpha$-Alumina. J. Phys. Chem. C 2007, 111 (49), 18164-18173. https://doi.org/10.1021/jp0741408.

(46) Wischert, R.; Laurent, P.; Copéret, C.; Delbecq, F.; Sautet, P. $\gamma$-Alumina: The Essential and Unexpected Role of Water for the Structure, Stability, and Reactivity of "Defect" Sites. J. Am. Chem. Soc. 2012, 134 (35), 14430-14449. https://doi.org/10.1021/ja3042383. 
(47) Siepmann, J. I.; Sprik, M. Influence of Surface Topology and Electrostatic Potential on Water/Electrode Systems. J. Chem. Phys. 1995, 102 (1), 511-524. https://doi.org/10.1063/1.469429.

(48) Spohr, E.; Heinzinger, K. Molecular Dynamics Simulation of a Water/Metal Interface. Chem. Phys. Lett. 1986, 123 (3), 218-221. https://doi.org/10.1016/0009-2614(86)800161.

(49) Steinmann, S. N.; Ferreira De Morais, R.; Götz, A. W.; Fleurat-Lessard, P.; Iannuzzi, M.; Sautet, P.; Michel, C. Force Field for Water over Pt(111): Development, Assessment, and Comparison. J. Chem. Theory Comput. 2018, 14 (6), 3238-3251. https://doi.org/10.1021/acs.jctc.7b01177.

(50) van Duin, A. C. T.; Dasgupta, S.; Lorant, F.; Goddard, W. A. ReaxFF: A Reactive Force Field for Hydrocarbons. J. Phys. Chem. A 2001, 105 (41), 9396-9409. https://doi.org/10.1021/jp004368u.

(51) Pitman, M. C.; van Duin, A. C. T. Dynamics of Confined Reactive Water in Smectite Clay-Zeolite Composites. J. Am. Chem. Soc. 2012, 134 (6), 3042-3053. https://doi.org/10.1021/ja208894m.

(52) Ojwang, J. G. O.; van Santen, R. A.; Kramer, G. J.; van Duin, A. C. T.; Goddard, W. A. Parametrization of a Reactive Force Field for Aluminum Hydride. J. Chem. Phys. 2009, 131 (4), 044501. https://doi.org/10.1063/1.3182853.

(53) Shchygol, G.; Yakovlev, A.; Trnka, T.; van Duin, A. C. T.; Verstraelen, T. ReaxFF Parameter Optimization with Monte-Carlo and Evolutionary Algorithms: Guidelines and Insights. J. Chem. Theory Comput. 2019, 15 (12), 6799-6812. https://doi.org/10.1021/acs.jctc.9b00769.

(54) Zeni, C.; Rossi, K.; Glielmo, A.; Baletto, F. On Machine Learning Force Fields for Metallic Nanoparticles. Adv. Phys. $X$ 2019, $4 \quad$ (1), 1654919. https://doi.org/10.1080/23746149.2019.1654919.

(55) Singraber, A.; Behler, J.; Dellago, C. Library-Based LAMMPS Implementation of HighDimensional Neural Network Potentials. J. Chem. Theory Comput. 2019, 15 (3), 18271840. https://doi.org/10.1021/acs.jctc.8b00770.

(56) Dral, P. O. Quantum Chemistry in the Age of Machine Learning. J. Phys. Chem. Lett. 2020, 11 (6), 2336-2347. https://doi.org/10.1021/acs.jpclett.9b03664.

(57) Gkeka, P.; Stoltz, G.; Barati Farimani, A.; Belkacemi, Z.; Ceriotti, M.; Chodera, J. D.; Dinner, A. R.; Ferguson, A. L.; Maillet, J.-B.; Minoux, H.; Peter, C.; Pietrucci, F.; Silveira, A.; Tkatchenko, A.; Trstanova, Z.; Wiewiora, R.; Lelièvre, T. Machine Learning Force Fields and Coarse-Grained Variables in Molecular Dynamics: Application to Materials and Biological Systems. J. Chem. Theory Comput. 2020, 16 (8), 4757-4775. https://doi.org/10.1021/acs.jctc.0c00355.

(58) Bartók, A. P.; De, S.; Poelking, C.; Bernstein, N.; Kermode, J. R.; Csányi, G.; Ceriotti, M. Machine Learning Unifies the Modeling of Materials and Molecules. Sci. Adv. 2017, 3 (12), e1701816. https://doi.org/10.1126/sciadv.1701816.

(59) Natarajan, S. K.; Behler, J. Neural Network Molecular Dynamics Simulations of SolidLiquid Interfaces: Water at Low-Index Copper Surfaces. Phys. Chem. Chem. Phys. 2016, 18 (41), 28704-28725. https://doi.org/10.1039/C6CP05711J.

(60) Quaranta, V.; Behler, J.; Hellström, M. Structure and Dynamics of the LiquidWater/Zinc-Oxide Interface from Machine Learning Potential Simulations. J. Phys. Chem. C 2019, 123 (2), 1293-1304. https://doi.org/10.1021/acs.jpcc.8b10781.

(61) Chen, Y.; Huang, Y.; Cheng, T.; Goddard, W. A. Identifying Active Sites for CO Reduction on Dealloyed Gold Surfaces by Combining Machine Learning with Multiscale Simulations. J. Am. Chem. Soc. 2019, 141 (29), 11651-11657. https://doi.org/10.1021/jacs.9b04956. 
(62) Noé, F.; Tkatchenko, A.; Müller, K.-R.; Clementi, C. Machine Learning for Molecular Simulation. Annu. Rev. Phys. Chem. 2020, 71 (1), 361-390. https://doi.org/10.1146/annurev-physchem-042018-052331.

(63) Clabaut, P.; Fleurat-Lessard, P.; Michel, C.; Steinmann, S. N. Ten Facets, One Force Field: The GAL19 Force Field for Water-Noble Metal Interfaces. J. Chem. Theory Comput. 2020, 16 (7), 4565-4578. https://doi.org/10.1021/acs.jctc.0c00091.

(64) Hutter, J.; Iannuzzi, M.; Schiffmann, F.; VandeVondele, J. CP2K: Atomistic Simulations of Condensed Matter Systems. Wiley Interdiscip. Rev. Comput. Mol. Sci. 2014, 4 (1), 1525. https://doi.org/10.1002/wcms.1159.

(65) Perdew, J. P.; Burke, K.; Ernzerhof, M. Generalized Gradient Approximation Made Simple. Phys. Rev. Lett. 1996, 77 (18), 3865-3868. https://doi.org/10.1103/PhysRevLett.77.3865.

(66) Grimme, S.; Antony, J.; Ehrlich, S.; Krieg, H. A Consistent and Accurate Ab Initio Parametrization of Density Functional Dispersion Correction (DFT-D) for the 94 Elements H-Pu. J Chem Phys 2010, 132 (15), 154104. https://doi.org/10.1063/1.3382344.

(67) Grimme, S.; Ehrlich, S.; Goerigk, L. Effect of the Damping Function in Dispersion Corrected Density Functional Theory. J. Comput. Chem. 2011, 32 (7), 1456-1465. https://doi.org/10.1002/jcc.21759.

(68) Hartwigsen, C.; Goedecker, S.; Hutter, J. Relativistic Separable Dual-Space Gaussian Pseudopotentials from $\mathrm{H}$ to Rn. Phys. Rev. $B$ 1998, 58 (7), 3641-3662. https://doi.org/10.1103/PhysRevB.58.3641.

(69) Goedecker, S.; Teter, M.; Hutter, J. Separable Dual-Space Gaussian Pseudopotentials. Phys. Rev. B 1996, 54 (3), 1703-1710. https://doi.org/10.1103/PhysRevB.54.1703.

(70) Krack, M. Pseudopotentials for $\mathrm{H}$ to $\mathrm{Kr}$ Optimized for Gradient-Corrected ExchangeCorrelation Functionals. Theor. Chem. Acc. 2005, 114 (1-3), 145-152. https://doi.org/10.1007/s00214-005-0655-y.

(71) VandeVondele, J.; Hutter, J. Gaussian Basis Sets for Accurate Calculations on Molecular Systems in Gas and Condensed Phases. J. Chem. Phys. 2007, 127 (11), 114105. https://doi.org/10.1063/1.2770708.

(72) Lippert, G.; Hutter, J.; Parrinello, M. A Hybrid Gaussian and Plane Wave Density Functional Scheme. Mol. Phys. 1997, 92 (3), 477-487. https://doi.org/10.1080/00268979709482119.

(73) VandeVondele, J.; Krack, M.; Mohamed, F.; Parrinello, M.; Chassaing, T.; Hutter, J. Quickstep: Fast and Accurate Density Functional Calculations Using a Mixed Gaussian and Plane Waves Approach. Comput. Phys. Commun. 2005, 167 (2), 103-128. https://doi.org/10.1016/j.cpc.2004.12.014.

(74) An, J.; Wanaguru, P.; Xia, C.; Tao, M.; Zhang, Q. First-Principles Study of Sulfur Atom Doping and Adsorption on $\alpha-F e 2 O 3$ (0001) Film. Phys. Lett. A 2016, 380 (38), 31493154. https://doi.org/10.1016/j.physleta.2016.07.042.

(75) Digne, M.; Sautet, P.; Raybaud, P.; Euzen, P.; Toulhoat, H. Hydroxyl Groups on $\gamma$ Alumina Surfaces: A DFT Study. J. Catal. 2002, 211 (1), 1-5. https://doi.org/10.1006/jcat.2002.3741.

(76) Monkhorst, H. J.; Pack, J. D. Special Points for Brillouin-Zone Integrations. Phys. Rev. B 1976, 13 (12), 5188-5192. https://doi.org/10.1103/PhysRevB.13.5188.

(77) He, Y.; Guo, F.; Yang, K. R.; Heinlein, J. A.; Bamonte, S. M.; Fee, J. J.; Hu, S.; Suib, S. L.; Haller, G. L.; Batista, V. S.; Pfefferle, L. D. In Situ Identification of Reaction Intermediates and Mechanistic Understandings of Methane Oxidation over Hematite: A Combined Experimental and Theoretical Study. J. Am. Chem. Soc. 2020, jacs.0c07179. https://doi.org/10.1021/jacs.0c07179. 
(78) Ewen, J. P.; Gattinoni, C.; Morgan, N.; Spikes, H. A.; Dini, D. Nonequilibrium Molecular Dynamics Simulations of Organic Friction Modifiers Adsorbed on Iron Oxide Surfaces. Langmuir 2016, 32 (18), 4450-4463. https://doi.org/10.1021/acs.langmuir.6b00586.

(79) Gouron, A.; Le Mapihan, K.; Camperos, S.; Al Farra, A.; Lair, V.; Ringuedé, A.; Cassir, M.; Diawara, B. New Insights in Self-Assembled Monolayer of Imidazolines on Iron Oxide Investigated by DFT. Appl. Surf. Sci. 2018, 456, 437-444. https://doi.org/10.1016/j.apsusc.2018.06.119.

(80) Essmann, U.; Perera, L.; Berkowitz, M. L.; Darden, T.; Lee, H.; Pedersen, L. G. A Smooth Particle Mesh Ewald Method. J. Chem. Phys. 1995, 103 (19), 8577-8593. https://doi.org/10.1063/1.470117.

(81) Wang, J.; Wolf, R. M.; Caldwell, J. W.; Kollman, P. A.; Case, D. A. Development and Testing of a General Amber Force Field. J. Comput. Chem. 2004, 25 (9), 1157-1174. https://doi.org/10.1002/jcc.20035.

(82) Gasteiger, J.; Marsili, M. Iterative Partial Equalization of Orbital Electronegativity - a Rapid Access to Atomic Charges. Tetrahedron 1980, 36 (22), 3219-3228. https://doi.org/10.1016/0040-4020(80)80168-2.

(83) O’Boyle, N. M.; Banck, M.; James, C. A.; Morley, C.; Vandermeersch, T.; Hutchison, G. R. Open Babel: An Open Chemical Toolbox. J. Cheminformatics 2011, 3 (1), 33. https://doi.org/10.1186/1758-2946-3-33.

(84) Jorgensen, W. L.; Chandrasekhar, J.; Madura, J. D.; Impey, R. W.; Klein, M. L. Comparison of Simple Potential Functions for Simulating Liquid Water. J. Chem. Phys. 1983, 79 (2), 926-935. https://doi.org/10.1063/1.445869.

(85) Weiner, S. J.; Kollman, P. A.; Nguyen, D. T.; Case, D. A. An All Atom Force Field for Simulations of Proteins and Nucleic Acids: An All Atom Force Field. J. Comput. Chem. 1986, 7 (2), 230-252. https://doi.org/10.1002/jcc.540070216.

(86) Case, D. A.; Cerutti, D. S.; Cheatham, T. E.; Darden, T. A.; Duke, R. E.; Giese, T. J.; Gohlke, H.; Goetz, A. W.; Greene, D.; Homeyer, N.; Izadi, S.; Kovalenko, A.; Lee, T. S.; LeGrand, S.; Li, P.; Lin, C.; J. Liu; Luo, R.; Mermelstein, D.; Merz, K. M.; Monard, G.; Nguyen, H.; Omelyan, I.; Onufrief, A.; Pan, F.; Qi, R.; Roe, D. R.; Roitberg, A.; Sagui, C.; Simmerling, C. L.; Botello-Smith, W. M.; Swails, J.; Walker, R. C.; Wang, J.; Wolf, R. M.; Wu, X.; Xiao, L.; York, D. M.; Kollman, P. A. AMBER 2017; University of California, San Francisco, 2017.

(87) Halgren, T. A. The Representation of van Der Waals (VdW) Interactions in Molecular Mechanics Force Fields: Potential Form, Combination Rules, and VdW Parameters. $J$. Am. Chem. Soc. 1992, 114 (20), 7827-7843. https://doi.org/10.1021/ja00046a032.

(88) Berg, A.; Peter, C.; Johnston, K. Evaluation and Optimization of Interface Force Fields for Water on Gold Surfaces. J. Chem. Theory Comput. 2017, 13 (11), 5610-5623. https://doi.org/10.1021/acs.jctc.7b00612.

(89) Van Vleet, M. J.; Misquitta, A. J.; Stone, A. J.; Schmidt, J. R. Beyond Born-Mayer: Improved Models for Short-Range Repulsion in Ab Initio Force Fields. J. Chem. Theory Comput. 2016, 12 (8), 3851-3870. https://doi.org/10.1021/acs.jctc.6b00209.

(90) Wang, X.; Ramírez-Hinestrosa, S.; Dobnikar, J.; Frenkel, D. The Lennard-Jones Potential: When (Not) to Use It. Phys. Chem. Chem. Phys. 2020, 22 (19), 10624-10633. https://doi.org/10.1039/C9CP05445F.

(91) Martínez, L.; Andrade, R.; Birgin, E. G.; Martínez, J. M. PACKMOL: A Package for Building Initial Configurations for Molecular Dynamics Simulations. J. Comput. Chem. 2009, 30 (13), 2157-2164. https://doi.org/10.1002/jcc.21224.

(92) Chen, Y.; Elhag, A. S.; Reddy, P. P.; Chen, H.; Cui, L.; Worthen, A. J.; Ma, K.; Quintanilla, H.; Noguera, J. A.; Hirasaki, G. J.; Nguyen, Q. P.; Biswal, S. L.; Johnston, K. P. Phase Behavior and Interfacial Properties of a Switchable Ethoxylated Amine 
Surfactant at High Temperature and Effects on CO2-in-Water Foams. J. Colloid Interface Sci. 2016, 470, 80-91. https://doi.org/10.1016/j.jcis.2016.02.028.

(93) Chen, Y.; Elhag, A. S.; Poon, B. M.; Cui, L.; Ma, K.; Liao, S. Y.; Reddy, P. P.; Worthen, A. J.; Hirasaki, G. J.; Nguyen, Q. P.; Biswal, S. L.; Johnston, K. P. Switchable Nonionic to Cationic Ethoxylated Amine Surfactants for CO2 Enhanced Oil Recovery in HighTemperature, High-Salinity Carbonate Reservoirs. SPE J. 2014, 19 (02), 249-259. https://doi.org/10.2118/154222-PA.

(94) Dawczyk, J.; Russo, J.; Spikes, H. Ethoxylated Amine Friction Modifiers and ZDDP. Tribol. Lett. 2019, 67 (4), 106. https://doi.org/10.1007/s11249-019-1221-4.

(95) Pereira de Matos, Rafael. Molecular Dynamics Simulations of Amine-Based Friction Modifiers: Diffusion, Adsorption and Friction Behaviors, Lyon, Lyon, 2019.

(96) Wood, M. H.; Welbourn, R. J. L.; Charlton, T.; Zarbakhsh, A.; Casford, M. T.; Clarke, S. M. Hexadecylamine Adsorption at the Iron Oxide-Oil Interface. Langmuir 2013, 29 (45), 13735-13742. https://doi.org/10.1021/la4018147.

(97) Blanck, S.; Martì, C.; Loehlé, S.; Steinmann, S. N.; Michel, C. (Dis)Similarities of Adsorption of Diverse Functional Groups over Alumina and Hematite Depending on the Surface State. The Journal of Chemical Physics. accepted 2021. 